\title{
Clinical use of anti-TNF therapy and increased risk of infections
}

This article was published in the following Dove Press journal:

Drug, Healthcare and Patient Safety

27 March 2013

Number of times this article has been viewed

\author{
Tauseef $\mathrm{Ali}^{1,2}$ \\ Sindhu Kaitha ${ }^{2}$ \\ Sultan Mahmood ${ }^{2}$ \\ Abdul Ftesi ${ }^{3}$ \\ Jordan Stone ${ }^{2}$ \\ Michael S Bronze 2 \\ 'OU Physicians Center for \\ Inflammatory Bowel Disease, \\ University of Oklahoma Health \\ Sciences Center, ${ }^{2}$ Department \\ of Internal Medicine, University \\ of Oklahoma Health Sciences Center, \\ ${ }^{3}$ Integris Baptist Hospital, Oklahoma \\ City, Oklahoma, USA
}

\begin{abstract}
Biologics such as antitumor necrosis factor (anti-TNF) drugs have emerged as important agents in the treatment of many chronic inflammatory diseases, especially in cases refractory to conventional treatment modalities. However, opportunistic infections have become a major safety concern in patients on anti-TNF therapy, and physicians who utilize these agents must understand the increased risks of infection. A literature review of the published data on the risk of bacterial, viral, fungal, and parasitic infections associated with anti-TNF therapy was performed and the clinical presentation, diagnostic tests, management, and prevention of opportunistic infections in patients receiving anti-TNF therapy were reviewed. Awareness of the therapeutic potential and associated adverse events is necessary for maximizing therapeutic benefits while minimizing adverse effects from anti-TNF treatments. Patients should be adequately vaccinated when possible and closely monitored for early signs of infection. When serious infections occur, withdrawal of anti-TNF therapy may be necessary until the infection has been identified and properly treated.
\end{abstract}

Keywords: anti-TNF therapy, infections

\section{Introduction}

Tumor necrosis factor- $\alpha(\mathrm{TNF}-\alpha)$ is a $26 \mathrm{kDa}$ homotrimeric transmembrane protein that is expressed on the surface of macrophages, T-lymphocytes, natural killer cells, smooth muscle cells, and fibroblasts. ${ }^{1}$ TNF- $\alpha$ is an important proinflammatory cytokine and has been implicated in the pathogenesis of many inflammatory and autoimmune diseases including rheumatoid arthritis, ${ }^{2}$ inflammatory bowel disease (IBD), and ankylosing spondylitis. ${ }^{3}$ The reduction of TNF- $\alpha$ levels by anti-TNF agents leads to reduced chronic pathologic inflammatory responses in these diseases. ${ }^{3}$ Currently available anti-TNF agents and their approved indications are listed in Table 1.

One of the major risks of using anti-TNF therapy is the small but significant risk of serious opportunistic infection. ${ }^{4-6}$ Opportunistic infection is defined as a usually serious and progressive infection by an organism that, under normal circumstances, possesses little or no pathologic capabilities. However, predisposing factors such as underlying disease or medical treatment can reduce a patient's immunity, permitting the organism to cause an infectious disease. ${ }^{7}$ Several risk factors place patients at higher risk for an opportunistic infection. Increased age leads to decreased innate immune function ${ }^{8}$ and increased risk of opportunistic infections. ${ }^{9}$ Malnutrition and micronutrient deficiency, which are common in patients with chronic disease, is associated with diminished immune function and increased risk of opportunistic infection. ${ }^{10}$ Exposure to opportunistic pathogens is also increased by living or traveling
Correspondence: Tauseef Ali I 345 WP, 920 SL Young Blvd, Oklahoma City, Oklahoma, USA

Tel 0 I 405 27I 5428

Fax 0 I 405 27| 5803

Email tauseef-ali@ouhsc.edu 
Table I Currently available anti-TNF agents, their mechanism of action, and approved indications

\begin{tabular}{|c|c|c|}
\hline Drug name & Mechanism of action & Approved indications \\
\hline $\begin{array}{l}\text { Infliximab (Remicade; Centocor, Inc, } \\
\text { Malvern, PA) }\end{array}$ & $\begin{array}{l}\text { Chimeric mouse FvI human IgGI TNF- } \alpha \text { monoclonal } \\
\text { antibody } y^{4,175}\end{array}$ & RA, PA, AS, UC, and CD ${ }^{84,176}$ \\
\hline $\begin{array}{l}\text { Adalimumab (Humira; Abbott } \\
\text { Laboratories, Abbott Park, IL) }\end{array}$ & Fully human recombinant IgGI TNF- $\alpha$ monoclonal antibody & $\mathrm{RA}, \mathrm{PA}, \mathrm{AS}, \mathrm{UC}$ and $\mathrm{CD}^{4}$ \\
\hline $\begin{array}{l}\text { Etanercept (Enbrel; Amgen, } \\
\text { Thousand Oaks, CA) }\end{array}$ & $\begin{array}{l}\text { Bivalent human TNFR2 receptor fused to the Fc portion } \\
\text { of human }\left.\lg G\right|^{177}\end{array}$ & $\mathrm{RA}, \mathrm{P}, \mathrm{PA}$, and $\mathrm{AS}^{4}$ \\
\hline $\begin{array}{l}\text { Certolizumab pegol (Cimzia; UCB, } \\
\text { Belgium) }\end{array}$ & $\begin{array}{l}\text { Fab' humanized fragment of an anti-TNF antibody attached } \\
\text { to a polyethylene glycol moiety (PEGylated) })^{177}\end{array}$ & $\mathrm{RA}$ and $C D^{177}$ \\
\hline $\begin{array}{l}\text { Golimumab (Simponi; Janssen Biotech, } \\
\text { Inc, Horsham, PA) }\end{array}$ & Fully human IgGI human TNF- $\alpha$ monoclonal antibody & $\mathrm{RA}, \mathrm{PA}$, and $\mathrm{AS} \mathrm{S}^{178}$ \\
\hline
\end{tabular}

Abbreviations: RA, rheumatoid arthritis; PA, psoriatic arthritis; P, psoriasis; AS, ankylosing spondylitis; UC, ulcerative colitis; CD, Crohn's disease.

in endemic areas, through occupational exposure, or through contaminated food and water. Comorbid diseases, such as diabetes mellitus or alcoholism, also increase the risk of opportunistic infections. ${ }^{11}$ Immunomodulatory therapy (eg, corticosteroids, methotrexate, azathioprine) and biologic therapy (eg, anti-TNF agents, other monoclonal antibodies), especially when used in combination, are associated with an increased risk of opportunistic infection. ${ }^{5,9}$ It must be noted, however, that the risk of opportunistic infection with combination therapy is low and each case should be evaluated to assess the risks and benefits of treatment options on disease activity.

\section{Mechanism of immune deficiency}

There are several proposed mechanisms of immune deficiency in patients receiving anti-TNF therapy. TNF- $\alpha$ is essential for the formation and maintenance of granulomas, ${ }^{5,6}$ therefore its inhibition can lead to increased risk of new tuberculosis infection, reactivation of latent tuberculosis, and can predispose to other granulomatous infections, such as Histoplasma capsulatum..$^{12}$ TNF- $\alpha$ plays a role in macrophage activation and differentiation and phagosome formation, and is critical for the clearance of intracellular pathogens (eg, Listeria, Legionella, Salmonella). ${ }^{5}$ Neutropenia can occur after antiTNF administration, predisposing to opportunistic infections such as Candida or Aspergillus. ${ }^{9}$ TNF- $\alpha$ is also important for immune responses against viral pathogens, and its inhibition could cause complications in patients infected with hepatitis B virus $(\mathrm{HBV})^{13}$ or varicella zoster virus (VZV), ${ }^{14}$ for example.

\section{Bacterial infections}

Anti-TNF therapy is associated with an increased risk of bacterial infections. Some common bacterial infections associated with the use of anti-TNF therapy are described below and summarized in Tables 2 and 3 .

\section{Mycobacterium tuberculosis}

The problem of tuberculosis (TB), caused by M. tuberculosis, has been increasing with the development of both multidrug-resistant and extensively drug-resistant organisms. The incidence of TB in the US population is reported to be 3.4 cases per $100,000 .{ }^{15}$ Reactivation of granulomatous infections is a serious complication in patients taking anti-TNF therapy. The relative risk for TB increases 1.6-25 times with anti-TNF therapy depending on the clinical context, the drug used, and the patient's country of origin. ${ }^{16}$ Pulmonary TB usually manifests as cough, weight loss, fatigue, fever, night sweats, chest pain, dyspnea, hemoptysis, anorexia, wasting, and malaise. It is important to remember that $>50 \%$ of reported TB cases associated with anti-TNF therapy are extrapulmonary, ${ }^{17}$ and can present as disseminated disease involving the lymph nodes, peritoneum, and pleura, or less commonly, it can cause meningeal, osteoarticular, or genitourinary tract disease. ${ }^{18} \mathrm{~TB}$ infection caused by inhalation of viable bacilli that persists in an inactive state is known as latent TB infection.

Tuberculin skin testing (TST) and interferon- $\gamma$ (IFN$\gamma)$ release assay are the two available screening tests for latent $\mathrm{TB}$, and the sensitivity of these tests is estimated to be $70 \%-90 \%$, and the specificity for all tests is $>95 \%$; an exception is that the TST in patients vaccinated with Bacillus Calmette-Guerin has $60 \%$ specificity owing to crossreactivity. ${ }^{19}$ The IFN- $\gamma$ release assay measures the release of IFN- $\gamma$ from a patient's T-cells when exposed to mycobacterial antigens, and may help overcome the confounding effect of Bacillus Calmette-Guerin vaccination because IFN- $\gamma$ release assay is more specific than $\mathrm{TST}^{20}{ }^{20}$ The sensitivity of TST may be enhanced by performing repeat examinations. For instance, a repeat TST after an initial negative test may enhance the sensitivity of detecting latent $\mathrm{TB},{ }^{21}$ and a second TST enhances the ability of achieving a reliable delayed-type 


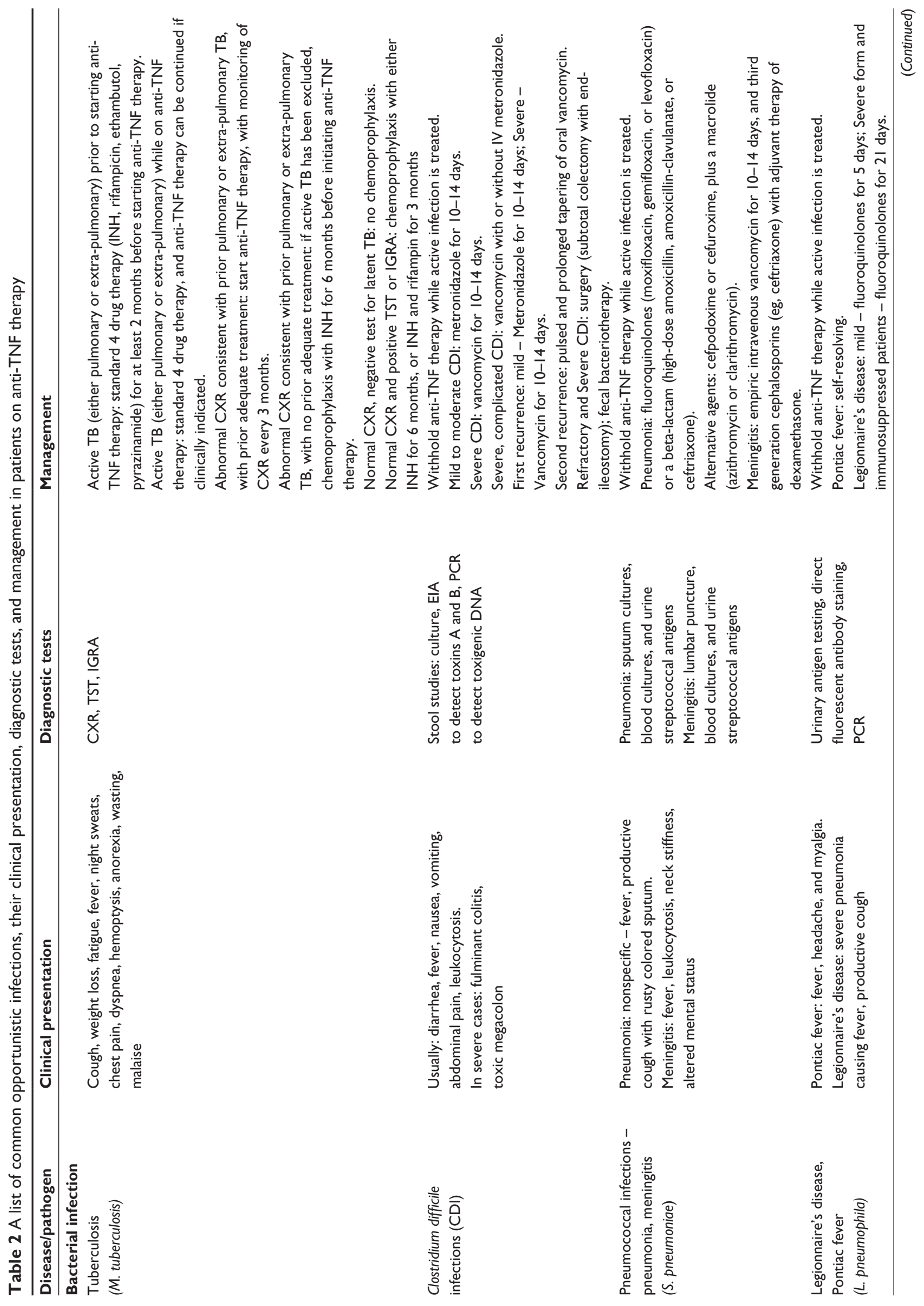



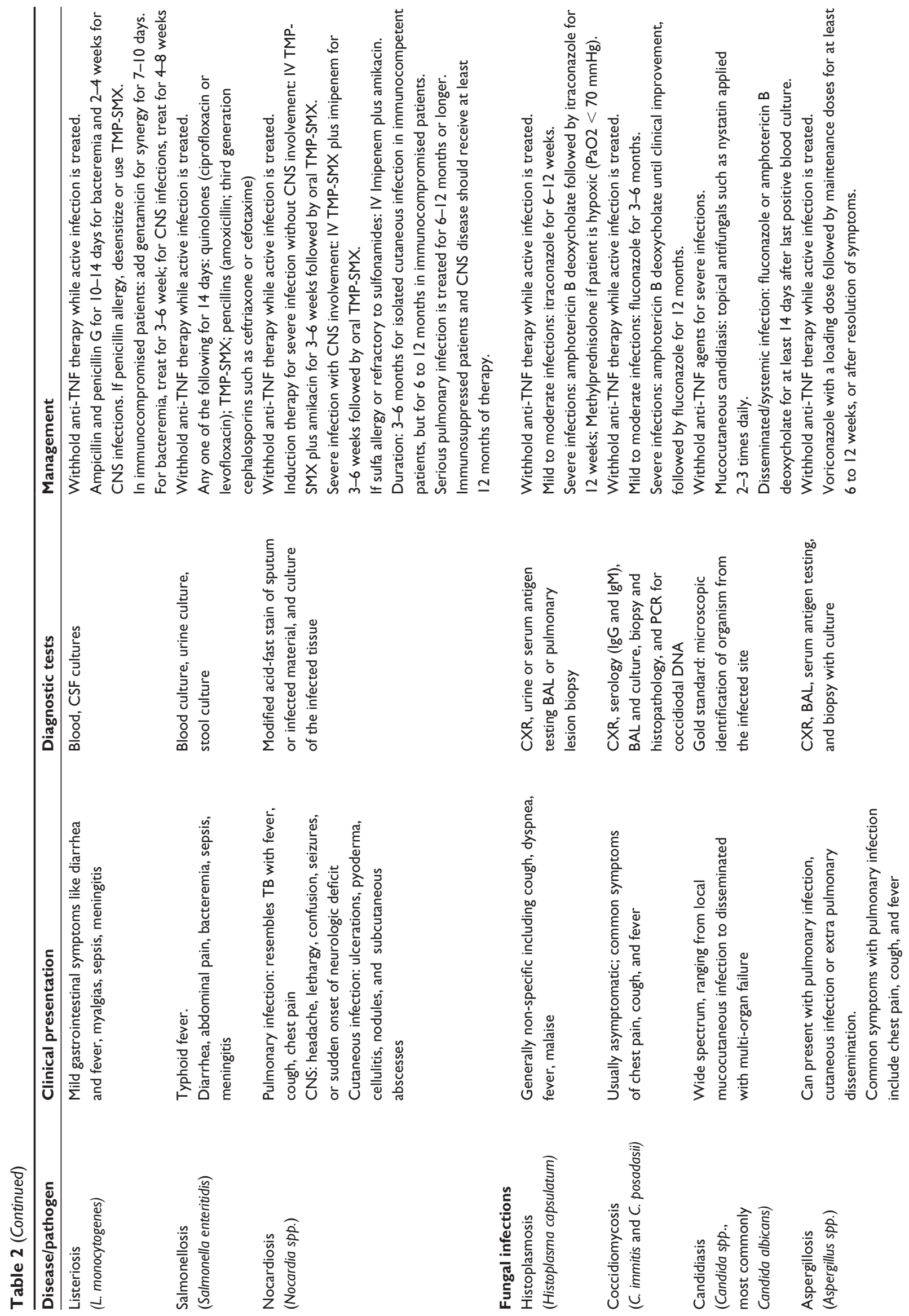

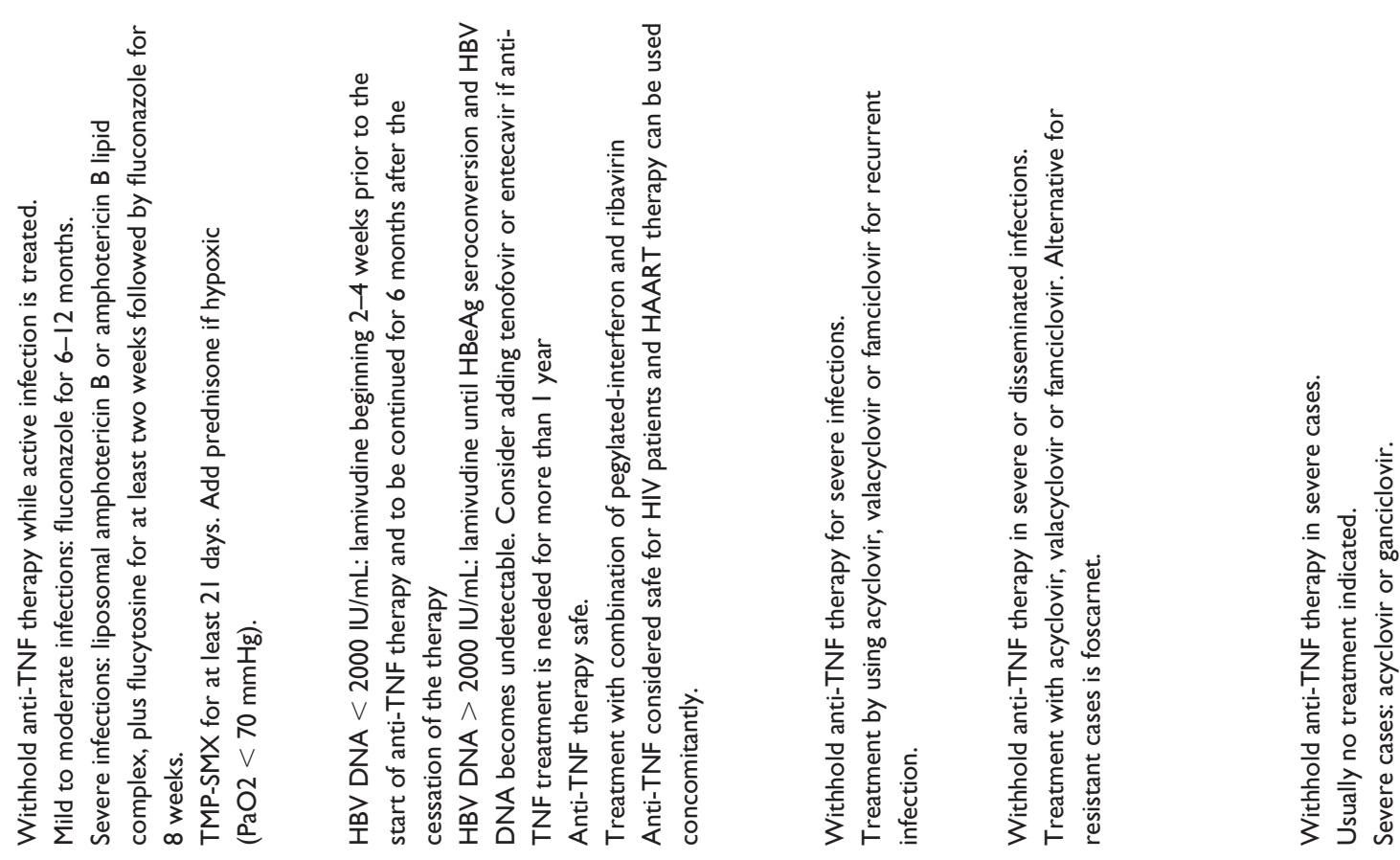

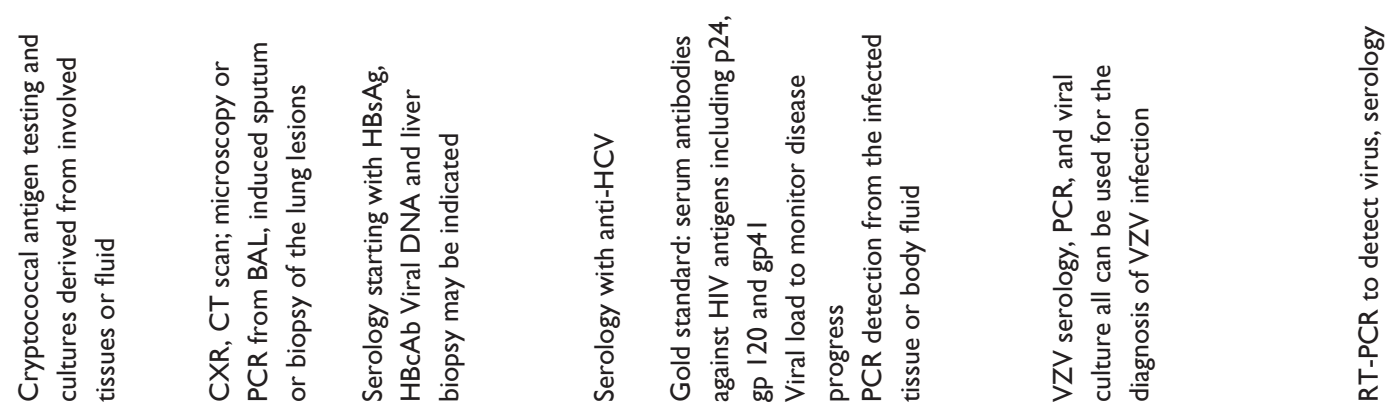
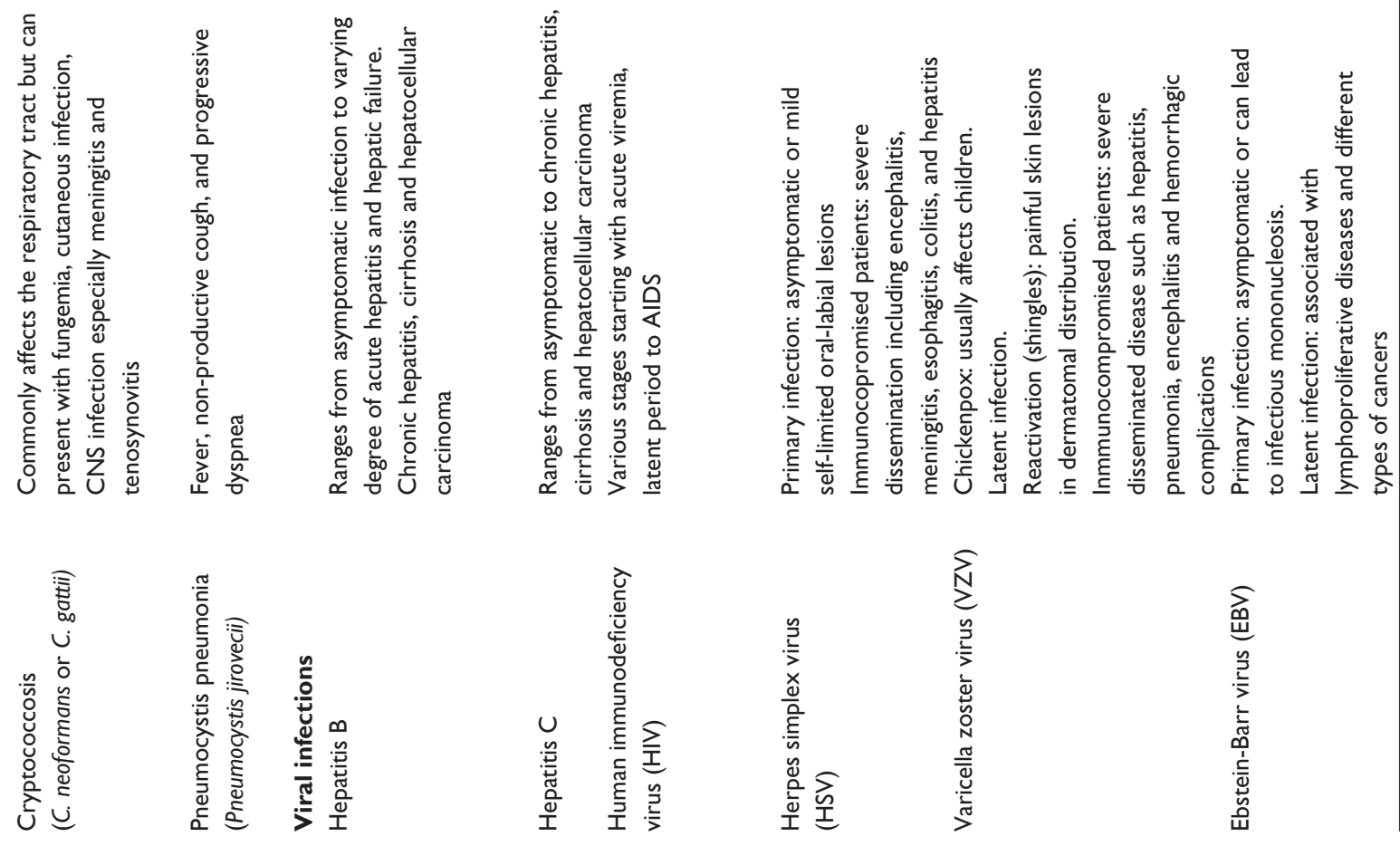


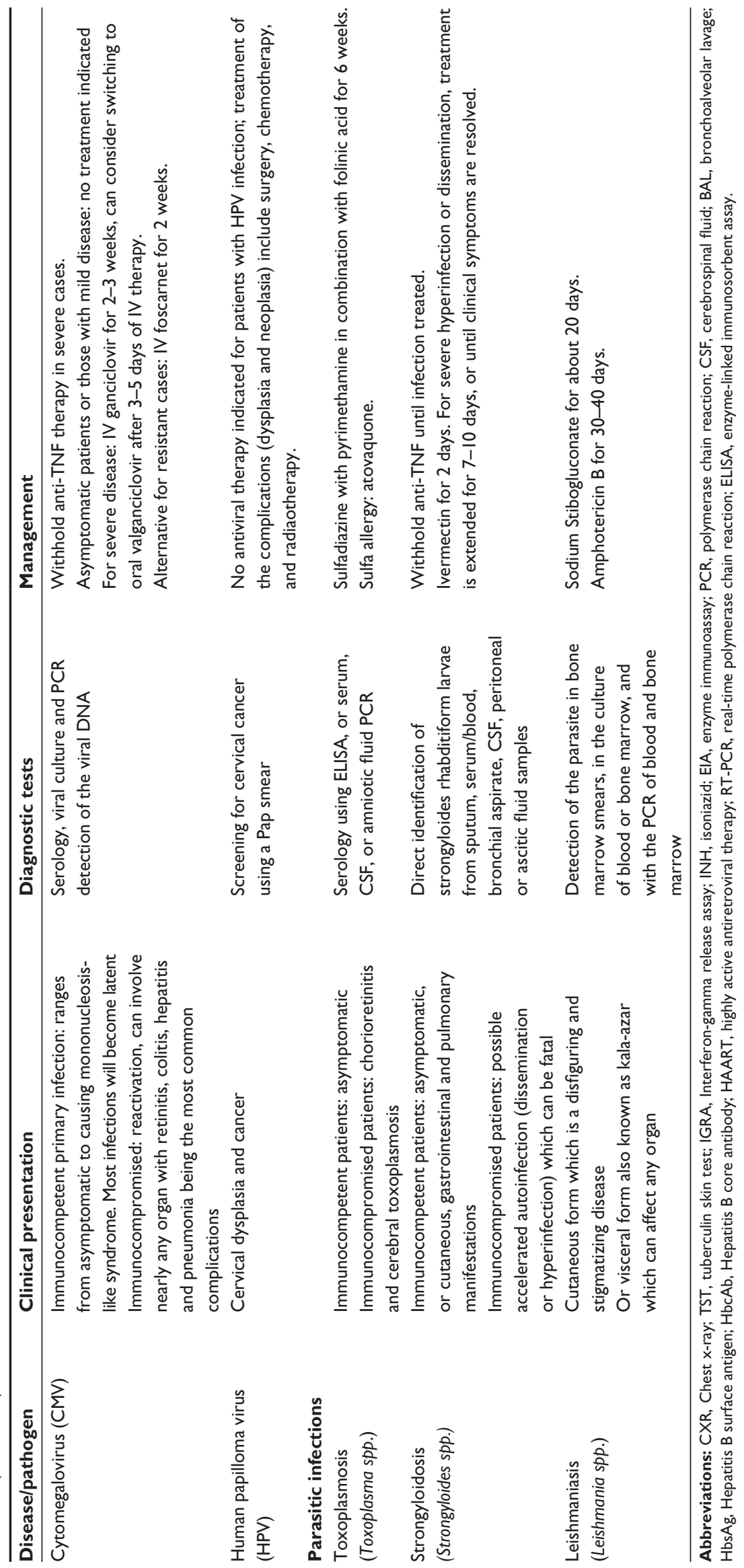


Table 3 Preventative measures for common opportunistic infections in patients on anti-TNF therapy

\begin{tabular}{|c|c|}
\hline Pathogen/disease & Preventative measures \\
\hline $\begin{array}{l}\text { Mycobacterium } \\
\text { tuberculosis }\end{array}$ & TB screening prior to initiation of anti TNF therapy and regular TB screening while on therapy. \\
\hline \multirow[t]{3}{*}{ Clostridium difficile } & Minimize the use and duration of antibiotics and proton pump inhibitors \\
\hline & Implement strict infection-control practices like contact precautions and washing hands with soap and water \\
\hline & Educate health care workers and patients about CDI risk factors \\
\hline Streptococcus & PPSV23 and PCV13 vaccination preferably before initiation of anti TNF therapy \\
\hline \multicolumn{2}{|l|}{ pneumoniae } \\
\hline Legionella & Avoid contaminated water sources \\
\hline \multirow[t]{4}{*}{ Listeria } & Proper food handling techniques like washing cucumbers or melons before consuming, rinsing raw fruits and vegetables \\
\hline & before cutting, cooking meat and poultry thoroughly \\
\hline & Avoid unpasteurized milk, and properly store refrigerated foods \\
\hline & $\begin{array}{l}\text { Pregnant and immunosupressed patients should avoid coleslaw, cheeses made of unpasteurized milk, deli meats, and } \\
\text { refrigerated seafood }\end{array}$ \\
\hline \multirow[t]{2}{*}{ Salmonella } & Safe food handling practices \\
\hline & $\begin{array}{l}\text { Improving food safety in restaurants and at home by properly cooking raw eggs, avoiding unpasteurized milk and } \\
\text { improperly cooked meat, oysters, ground beef and poultry }\end{array}$ \\
\hline \multirow[t]{3}{*}{ Pneumocystis jirovecii } & $\begin{array}{l}\text { For patients on triple immunomodulator therapy with one of agents being anti-TNF therapy or calcineur ininhibitor, } \\
\text { chemoprohylaxis with TMP-SMX ( } 80-400 \mathrm{mg} \text { daily) is recommended }\end{array}$ \\
\hline & For patients on double immunomodulators, with one of these being a calcineurin inhibitor or anti-TNF therapy, \\
\hline & prophylaxis can be considered but recommendations are still unclear \\
\hline Hepatitis B virus & $\begin{array}{l}\text { Screening with serology }(\mathrm{HBs} A g, \mathrm{HBcAb}) \text { and vaccination for those who are seronegative is strongly recommended for all } \\
\text { patients who might be considered for anti-TNF therapy }\end{array}$ \\
\hline Hepatitis C virus & No indication for screening or chemoprophylaxis \\
\hline HIV & General measures including safe sex, avoiding shared needles \\
\hline Herpes simplex virus & No indication for screening or chemoprophylaxis, no vaccination is available \\
\hline \multirow[t]{2}{*}{ Varicella zoster virus } & Varicella vaccine if no immunity to varicella and Zoster vaccine in patient with 60 years or above age. \\
\hline & $\begin{array}{l}\text { Passive vaccination with VZV IgG is also recommended for seronegative patients with close contact to patients with } \\
\text { active VZV infection }\end{array}$ \\
\hline Ebstein-Barr virus & No indication for screening or chemoprophylaxis, no vaccination is available \\
\hline Cytomegalovirus & No indication for screening or chemoprophylaxis, no vaccination is available \\
\hline \multirow[t]{2}{*}{ Human papilloma virus } & Primary prevention with vaccination is recommended for all females aged II or more \\
\hline & Screening with cervical Pap smear starting at age of 21 or within 3 years of becoming sexually active \\
\hline Toxoplasma & $\begin{array}{l}\text { Avoid eating under cooked meat, use gloves when cleaning cat filter boxes. Secondary prophylaxis in certain } \\
\text { immunosuppressed patients (such as HIV) }\end{array}$ \\
\hline \multirow[t]{2}{*}{ Strongyloides } & Screening of people coming from endemic areas \\
\hline & $\begin{array}{l}\text { Chemoprophylaxis with ivermectin ( } 200 \mathrm{mcg} / \mathrm{kg} \text { per day) for } 2 \text { days every } 2 \text { weeks for those with history of chronic } \\
\text { infection to prevent hyperinfection/disseminated infection }\end{array}$ \\
\hline Lishmania & Chemoprophylaxis may be indicated in certain immunosupressed patients ( such as HIV) \\
\hline
\end{tabular}

Abbreviations: BCG, Bacille Calmette-Guérin; TST, tuberculin skin test; CDI, Clostridium difficile infection; PPSV23, 23-valent pneumococcal vaccine; PCVI3, I3-valent pneumococcal conjugate vaccine; TMP-SMX, Trimethoprim-Sulfamethoxazole; $\mathrm{HBsAg}$, Hepatitis B surface antigen; HBcAb, Hepatitis B core antibody.

hypersensitivity reaction - this "booster phenomenon" results in fewer false-negative results. ${ }^{22}$

Before starting anti-TNF therapy, a history of prior TB infection should be determined and a careful physical examination, chest radiograph, and TST or IFN- $\gamma$ release assay should be performed. Patients who develop active TB (either pulmonary or extrapulmonary) prior to starting anti-TNF therapy are treated with standard four-drug therapy, which includes isoniazid, rifampicin, ethambutol, and pyrazinamide, and they should receive a minimum of 2 months of standard fourdrug therapy supervised by an infectious diseases specialist before starting anti-TNF therapy. Ideally, anti-TNF therapy should be delayed until a full course of anti-TB treatment is completed. ${ }^{23}$ Patients who develop active TB (either pulmonary or extrapulmonary) while on anti-TNF therapy are treated with standard four-drug therapy, and the anti-TNF therapy can be continued if clinically indicated. ${ }^{23}$ Patients with an abnormal chest radiograph consistent with prior pulmonary or extrapulmonary TB, who have received adequate treatment, can be started on anti-TNF therapy - these patients should be monitored with a chest radiograph every 3 months and should have sputum culture obtained if symptoms of TB develop. ${ }^{17}$ Patients with an abnormal chest radiograph consistent with prior pulmonary or extrapulmonary $\mathrm{TB}$, who have not received adequate treatment, should be ruled out for active TB before initiating anti-TNF treatment. If active TB has been excluded, 
chemoprophylaxis with isoniazid for 6 months is suggested before initiating anti-TNF therapy. If delaying anti-TNF therapy is not advisable, this should be discussed with the patient and an infectious disease specialist. ${ }^{17,23}$

In patients with a normal chest radiograph in whom anti-TNF therapy is planned, the next step in management is based on the results of TST or IFN- $\gamma$ release assay testing. For patients with negative tests for latent TB, no chemoprevention is recommended. Patients with a positive TST or IFN- $\gamma$ release assay should receive chemoprophylaxis with either isoniazid for 6 months, or isoniazid and rifampin for 3 months. ${ }^{23}$ All patients should be closely monitored. In patients receiving anti-TNF therapy, serial TB screening tests are indicated to identify patients with reactivation of latent TB or new TB exposure; however, the frequency and best screening methods have not been determined. ${ }^{24}$

\section{Clostridium difficile}

C. difficile is a Gram-positive, spore-forming anaerobic bacillus. There has been a significant increase in the proportion of hospitalizations complicated by $C$. difficile infection (CDI) from 1998-2004 (7/1000 versus 11/1000; $P<0.05) .{ }^{25}$ Acquisition of the infection occurs more frequently in those with recognized risk factors, including age $>65$ years, prolonged hospitalization, solid organ transplantation, immunosuppression, use of high risk medications (eg, corticosteroids, anti-TNF therapy, antibiotics such as cephalosporin, clindamycin, and fluoroquinolones), and IBD (ulcerative colitis, Crohn's disease). ${ }^{26} \mathrm{CDI}$ is usually a nosocomial infection, but community-acquired infections are also reported and associated with significant mortality. ${ }^{26,27}$ Clinically, patients with CDI can present with nausea, vomiting, diarrhea, fever, leukocytosis, abdominal pain, and in severe cases with toxic megacolon and fulminant colitis. Hospitalized patients with unexplained leukocytosis, even in the absence of diarrhea, should be tested for $C$. difficile. ${ }^{28}$ Hypervirulent strain NAP1/B1/027 of $C$. difficile is associated with severe disease and resistance to conventional medical therapy. ${ }^{27}$

There are multiple modalities available for diagnosing CDI. Stool culture for $C$. difficile is highly sensitive but labor intensive. Enzyme immunoassay testing to detect toxins A and $\mathrm{A}+\mathrm{B}$ is relatively simple and inexpensive. Recently, polymerase chain reaction (PCR) to detect toxigenic DNA has been adopted as the test of choice in many hospitals and health care facilities. ${ }^{28}$ The sensitivity and specificity for PCR is better than enzyme immunoassay ( $93 \%$ and $97 \%$ versus $73 \%$ and $97 \%$, respectively). ${ }^{29}$
For all CDI infections, anti-TNF therapy should be withheld until the active infection is properly treated. An initial episode of mild to moderate CDI (white blood cell count of $<15,000$ cells $/ \mu \mathrm{L}$ and a serum creatinine $<1.5$ times the premorbid level) is treated with metronidazole $(500 \mathrm{mg}$ orally three times daily) for 10-14 days. ${ }^{30}$ An initial episode of severe CDI (white blood cell count of $>15,000$ cells $/ \mu \mathrm{L}$ and serum creatinine $>1.5$ times the premorbid level) is treated with vancomycin (125 mg orally four times daily) for 10-14 days. ${ }^{30}$ For severe, complicated CDI manifested by hypotension, ileus, toxic megacolon, colonic perforation, lack of response to therapy, or a need for intensive care unit admission or colectomy, vancomycin (500 mg orally four times daily) is administered with or without metronidazole $(500 \mathrm{mg}$ intravenously [IV] every 8 hours). ${ }^{30}$ The first recurrence of CDI is treated similarly as an initial episode; metronidazole may be used for mild CDI relapse, and vancomycin for severe relapse. ${ }^{30}$ A second recurrence is treated with pulsed and prolonged tapering of oral vancomycin (125 mg four times daily for 10-14 days, $125 \mathrm{mg}$ twice daily for a week, $125 \mathrm{mg}$ once daily for a week, and then $125 \mathrm{mg}$ every 2-3 days for 2-8 weeks). ${ }^{30}$ Two recent trials have compared the efficacy of vancomycin (125 mg four times daily) with fidaxomicin (200 mg twice daily) given over 10 days. The rate of clinical cure was similar in both treatment groups ( $88 \%$ fidaxomicin versus $86 \%$ vancomycin) $;{ }^{31}$ however, the rate of recurrent CDI was significantly lower in the fidaxomicin arm (15\%) compared to those treated with vancomycin. Rifaximin has also been used to successfully treat recurrent CDI, including in IBD patients. ${ }^{32}$ Early surgical consultation is recommended in refractory or severe CDI as a delay in surgery has been associated with substantial morbidity and mortality. Surgical candidates include those patients with leukocytosis $\left(>15,000 / \mathrm{mm}^{3}\right)$, elevated serum lactate, or underlying IBD. ${ }^{33,34}$ Subtotal colectomy with end ileostomy is preferred over hemicolectomy or segmental resection. ${ }^{26}$ Recently, fecal bacteriotherapy has been used for severe and recurrent CDIs not responding to medical therapy. ${ }^{35}$ A systematic review of 27 case series and reports of patients treated with fecal transplant for recurrent and severe CDI reported disease resolution in $92 \%$ of patients. ${ }^{36} \mathrm{CDI}$ preventive measures include minimizing the use and duration of antibiotics and proton pump inhibitors, implementing strict infection-control practices, washing hands with soap and water, and educating health care workers and patients about CDI risk factors. Alcohol-based hand disinfection is not effective in preventing CDI. Probiotics such as Saccharomyces boulardii, Lactobacillus, or brewer's yeast (Saccharomyces cerevisiae) are 
also increasingly used for recurrent CDI, but their efficacy remains in question. ${ }^{26}$

\section{Streptococcus pneumoniae}

$S$. pneumonia is an encapsulated Gram-positive bacterium often referred to as pneumococcus. The organism is a leading bacterial cause of otitis media, sinusitis, and communityacquired pneumonia. In immunocompromised patients it can cause disseminated or invasive infections such as meningitis and bacteremia, and infections like necrotizing fasciitis and septic arthritis have also been reported.$^{37}$ Anti-TNF therapy diminishes humoral and cellular immunity, leaving patients more susceptible to invasive pneumococcal infections. Pneumococcal pneumonia can present clinically with fever and a productive cough with rusty-colored sputum. Pneumococcal meningitis presents with fever, leukocytosis, neck stiffness, and altered mental status. Sputum cultures, blood cultures, and urine streptococcal antigens are usually obtained from suspected patients prior to giving antibiotics.

Anti-TNF therapy should always be withheld until an active pneumococcal infection is treated. The choice of antibiotic depends on the resistance and local epidemiological data. Empirical treatment options for patients with communityacquired pneumonia include fluoroquinolones (moxifloxacin $400 \mathrm{mg}$ daily, gemifloxacin $320 \mathrm{mg}$ daily, or levofloxacin $750 \mathrm{mg}$ once daily) or a $\beta$-lactam (first-line agents: high-dose amoxicillin $1 \mathrm{~g}$ three times daily, amoxicillin-clavulanate $2 \mathrm{~g}$ twice daily, or ceftriaxone $1 \mathrm{~g}$ daily; alternative agents: cefpodoxime $200 \mathrm{mg}$ twice daily or cefuroxime $500 \mathrm{mg}$ twice daily), plus a macrolide (azithromycin $500 \mathrm{mg}$ on the first day followed by $250 \mathrm{mg}$ /day for 4 days or clarithromycin $250 \mathrm{mg}$ twice daily). ${ }^{38}$ Empirical treatment of meningitis should be treated with IV vancomycin (15-20 mg/kg IV every 12 hours for 10-14 days) and a third-generation cephalosporin such as ceftriaxone ( $2 \mathrm{~g}$ IV every 12 hours) until antibiotic susceptibility is known. Adjunctive therapy with dexamethasone (10 mg IV every 6 hours for 4 days) should be considered in all cases of pneumococcal meningitis. ${ }^{39}$

Prevention of pneumococcal infection is largely accomplished through vaccination. The 23 -valent pneumococcal polysaccharide vaccine (PPSV23) should be administered to adults aged 19-64 years who are receiving immunosuppressive therapy. The Advisory Committee on Immunization Practices recommends routine use of 13-valent pneumococcal conjugate vaccine (PCV13) for adults with immunocompromised conditions aged $\geq 19$ years, followed by the PPSV23 vaccine. ${ }^{40}$ Anti-TNF therapy may impair the response to pneumococcal vaccination, so the vaccine is usually recommended $\geq 2-3$ weeks prior to starting antiTNF therapy. ${ }^{41}$

\section{Legionella}

Legionella pneumophila is a Gram-negative, aerobic, intracellular coccobacillus. It has been identified from multiple environmental sources including surface water, mud, thermally polluted lakes or streams, whirlpool spas, cooling towers, air-conditioning units, and humidifiers. ${ }^{42}$ It is an important cause of hospital-acquired and communityacquired pneumonia. Legionnaire's disease is a severe form of pneumonia caused by Legionella, and it is difficult to clinically distinguish Legionnaire's disease from pneumococcal pneumonia. Pontiac fever is a milder form of L. pneumophila infection and manifests with fever, headache, and myalgia, and spontaneously resolves in 3-5 days. ${ }^{43}$ Diagnosis is made with rapid diagnostic tests, such as urinary antigen testing, direct fluorescent antibody staining, or PCR. Less commonly, Legionella antibody tests such as indirect fluorescent antibody and enzyme-linked immunosorbent assay are used. Definitive diagnosis of Legionnaire's disease is based on isolation of Legionella from culture.

Fluoroquinolones, such as oral levofloxacin (750 mg once daily), are recommended for 5 days for mild forms of Legionella infection. In immunosuppressed patients who are severely ill from Legionnaire's disease, treatment should be extended to 21 days. $^{44}$ Macrolide antibiotics such as azithromycin (initial dose of $1 \mathrm{~g}$ on the first day followed by $500 \mathrm{mg}$ daily for 7-10 days) are also effective. In 2011, the US Food and Drug Administration (FDA) added a boxed warning about the risk of Legionella infection for the entire class of anti-TNF agents. ${ }^{45}$ Anti-TNF therapy should always be withheld until the active infection is resolved.

\section{Listeria monocytogenes}

L. monocytogenes is a small, aerobic, Gram-positive intracellular bacillus. Listeriosis most commonly affects newborns, pregnant women, older patients, and the immunocompromised, such as patients on immunomodulators, transplant patients, and patients with acquired immunodeficiency syndrome (AIDS). Listeriosis is a foodborne illness transmitted most commonly by melons, processed meats, hot dogs, soft cheeses, smoked seafood, and pâté. In non-neonatal forms, listeriosis presents with mild gastrointestinal symptoms like diarrhea, fever, and myalgia. Pregnant women may have a flu-like illness with fetal loss possible. In patients taking anti-TNF therapy, the infection is more invasive, causing sepsis and meningitis. 
Diagnosis is usually made by isolation of the pathogen in the blood or cerebrospinal fluid (CSF). Negative cultures may not completely rule out Listeria, especially when there is a high clinical suspicion. The infection is associated with a high mortality rate - up to $30 \%$ die despite medical therapy. ${ }^{46}$ In 2011, the FDA added a boxed warning about the risk of listeriosis for anti-TNF agents. In a report on granulomatous infectious diseases from the FDA Adverse Event Reporting System from 1998-2002, there were 38 cases of Listeria infection in patients taking anti-TNF agents. ${ }^{47} \mathrm{~A}$ search of the medical literature in 2011 identified 26 published cases of listeriosis in patients who had received anti-TNF therapy, including seven deaths. ${ }^{45}$

First-line agents to treat listeriosis are ampicillin $(2 \mathrm{~g}$ IV every 4 hours) and penicillin G (4 million units IV every 4 hours). The role of adding an aminoglycoside to penicillin-based treatment is debated. Penicillin-allergic patients should be desensitized if necessary, or treated with trimethoprim-sulfamethoxazole $(10-20 \mathrm{mg} / \mathrm{kg}$ /day IV of the trimethoprim component divided every 6-12 hours). ${ }^{48}$ In immunocompromised patients, 3-6 weeks of treatment is preferred in cases of bacteremia and 4-8 weeks in cases of central nervous system (CNS) infections. ${ }^{48,49}$ While the data regarding management of anti-TNF therapy is lacking in literature, it is recommended to withhold anti-TNF therapy until the Listeria infection is resolved. Usually the decision to resume anti-TNF therapy is individualized, weighing the risks and benefits of the treatment. Patients should be counseled regarding proper food handling techniques, like washing cucumbers or melons before consumption, rinsing raw fruits and vegetables before cutting, cooking meat and poultry thoroughly, avoiding unpasteurized milk, and properly storing refrigerated foods. Pregnant patients should avoid coleslaw, cheese made of unpasteurized milk, deli meats, and refrigerated seafood.

\section{Salmonella}

Salmonella spp are aerobic Gram-negative bacilli. Salmonellosis caused by Salmonella enteritidis is the most common bacterial cause of foodborne disease in the US..$^{50}$ International travel and consuming raw eggs or undercooked meat are some common risk factors for Salmonella infection. Infection can result in several syndromes including gastroenteritis, typhoid fever, bacteremia, sepsis, or meningitis. Salmonellosis should be suspected in an immunocompromised patient presenting with diarrhea, fever, and abdominal cramps. Immunocompromised patients can also present with Salmonella bacteremia without gastroenteritis, resulting in a higher mortality rate than similar infections in immunocompetent patients. ${ }^{51}$ Diagnosis is usually made by isolating Salmonella from blood, urine, or stool samples.

For active Salmonella infections, anti-TNF therapy should be withheld until the infection is properly treated. Antibiotics such as ciprofloxacin (500 mg orally twice daily) or levofloxacin (500 mg orally once daily), trimethoprimsulfamethoxazole $(160 \mathrm{mg} / 800 \mathrm{mg}$ orally twice daily), amoxicillin (500 mg orally three times daily), a thirdgeneration cephalosporin such as ceftriaxone (1-2 g IV once daily) or cefotaxime ( $2 \mathrm{~g}$ IV every 8 hours) for 14 days effectively treats salmonellosis. ${ }^{52-54}$ Attention to local antibiotic resistance patterns is required to aid empirical antibiotic choices. Patients with severe diarrhea should receive fluid rehydration. Safe food handling practices such as properly cooking raw eggs, avoiding unpasteurized milk, and avoiding improperly cooked meat, oysters, ground beef, and poultry should be practiced at home and in restaurants. No commercial vaccine is available other than for typhoid fever prevention.

\section{Nocardia}

Nocardia spp are filamentous, aerobic, Gram-positive, weakly acid-fast bacteria. Infection is acquired by inhalation, ingestion of contaminated food, and by direct inoculation. Immunocompromised persons are at greatest risk for Nocardia infection. ${ }^{55}$ Nocardiosis can present as an invasive pulmonary infection resembling TB, manifested by fever, cough, and chest pain. Hematogenous dissemination to the CNS can cause symptoms of headache, lethargy, confusion, seizures, or sudden onset of neurologic deficit. Cutaneous infection is through direct inoculation of the organism through skin from trauma or penetrating injury and presents with ulcerations, pyoderma, cellulitis, nodules, and subcutaneous abscesses. Diagnosis is made by modified acid-fast stain of sputum or infected material, and culture of the infected tissue.

Trimethoprim-sulfamethoxazole $(15 \mathrm{mg} / \mathrm{kg} / \mathrm{day}$ IV of the trimethoprim component in two to four divided doses) plus amikacin ( $7.5 \mathrm{mg} / \mathrm{kg}$ IV every 12 hours) is the first line of therapy. ${ }^{56}$ If the patient is allergic to sulfa drugs, desensitization should be performed when possible. Alternatively, imipenem (500 mg IV every 6 hours) plus amikacin ( $7.5 \mathrm{mg} / \mathrm{kg}$ IV every 12 hours) can be used. Combination drug therapy (sulfonamide, ceftriaxone, and amikacin) is recommended in patients not responding to standard antimicrobial treatment. Immunocompromised patients and those with CNS disease should receive induction 
therapy with trimethoprim-sulfamethoxazole $(15 \mathrm{mg} /$ $\mathrm{kg} /$ day IV of the trimethoprim component in two to four divided doses) plus imipenem (500 mg IV every 6 hours) for 3-6 weeks, followed by oral trimethoprim-sulfamethoxazole $(10 \mathrm{mg} / \mathrm{kg} /$ day of the trimethoprim component in two or three divided doses) for $\geq 12$ months with close clinical monitoring. ${ }^{56}$ Anti-TNF therapy should be withheld during active infection and can be resumed after successful treatment. ${ }^{57}$

\section{Fungal infections}

TNF- $\alpha$ is an essential cytokine for the formation and maintenance of granulomas, thereby a key host defense mechanism against intracellular pathogens. ${ }^{6}$ Increased use of anti-TNF therapy has been accompanied by reports of fungal infections such as histoplasmosis and blastomycosis, ${ }^{47}$ and anti-TNF therapy has been associated with both primary and reactivated fungal infections. In an attempt to increase awareness of this problem, in September 2008, the US FDA issued a "black box" warning alerting clinicians of the risks of certain endemic fungal infections in patients treated with anti-TNF therapy ${ }^{58}$ Some common fungal infections associated with the use of anti-TNF therapy are described below and summarized in Tables 2 and 3.

\section{Histoplasmosis}

Histoplasmosis is a common endemic mycosis caused by H. capsulatum. The infection is found worldwide, but is particularly common in North and Central America. In the US, the infection tends to occur more commonly in the Midwestern states, especially in the Ohio and Mississippi River valley regions. ${ }^{59}$ Potential exposures include demolition of old buildings, cleaning chicken coops, and spelunking. ${ }^{59}$ The infection primarily affects the lungs causing acute pneumonia. Disseminated disease occurs in approximately one in 2000 patients with acute infection and immunosuppression (eg, AIDS, solid organ transplantation, treatment with anti-TNF agents) has been identified as the most important risk factor for disseminated infection. ${ }^{60}$ Among patients on anti-TNF therapy, histoplasmosis has been identified as the most common cause of invasive fungal infection. ${ }^{61}$ Signs and symptoms are generally nonspecific with cough, dyspnea, fever, malaise, and interstitial pneumonitis on chest radiographs being commonly reported ${ }^{61}$ In patients suspected of having histoplasmosis, chest radiograph should be obtained, although they may be normal in $40 \%-70 \%$ of cases. Common chest radiograph findings include diffuse or localized infiltrates and/or hilar lymphadenopathy. ${ }^{62}$
One test used to diagnose Histoplasma infection is urine or serum antigen test. This test is done using an enzyme immunoassay and is useful for rapid diagnosis in severe infections. Biopsy of pulmonary lesions and bronchoalveolar lavage (BAL) may be required in some cases. ${ }^{63}$

Anti-TNF therapy needs to be discontinued in patients who develop histoplasmosis or other invasive fungal infections during therapy. ${ }^{64}$ For mild to moderate infections limited to the lungs, without systemic compromise, itraconazole (200-400 mg daily) for 6-12 weeks is the preferred treatment. For severe pulmonary or disseminated infections, the general approach is $1-2$ weeks of amphotericin B deoxycholate $(0.7-1.0 \mathrm{mg} / \mathrm{kg} /$ day $)$ followed by itraconazole (200 mg twice daily) for 12 weeks. Methylprednisolone can also be added for severe respiratory complications including hypoxemia (partial pressure of oxygen in arterial blood $<70 \mathrm{mmHg}$ ) ${ }^{65,66}$ Treatment response is monitored using Histoplasma antigen concentrations in the urine or serum. ${ }^{67}$ Treatment is usually very effective, except in patients with CNS histoplasmosis owing to the poor penetration of most antifungal agents into the CSF. Only $60 \%-80 \%$ of patients with Histoplasma meningitis respond to treatment with amphotericin B, and up to one-half of responders relapse during subsequent years. ${ }^{68}$ Resumption of anti-TNF therapy after successful treatment of histoplasmosis does not seem to increase the long-term risk of recurrence. ${ }^{62}$

\section{Coccidioidomycosis}

Coccidioidomycosis is caused by the dimorphic fungi of the genus Coccidioides (Coccidioides immitis and Coccidioides posadasii). The infection is spread by inhalation of spores. The fungus tends to be endemic in the southwestern US and parts of Central and South America. More than half of the illnesses are asymptomatic; among symptomatic patients, chest pain, cough, and fever are the most common manifestations. A chest radiograph may show a diffuse bilateral reticulonodular pattern that sometimes is indistinguishable from Pneumocystis pneumonia (PCP). A high index of suspicion of coccidioidomycosis infection in patients from endemic areas is necessary. BAL and culture, serology, biopsy, and histopathology and PCR for coccidioidal DNA can facilitate diagnosis. However, anticoccidioidal antibodies (immunoglobulin $\mathrm{G}$ and immunoglobulin $\mathrm{M}$ ) do not readily differentiate between new and old infection and can be falsely negative in immunocompromised patients. Coccidioidal antigen detection in urine may be helpful in diagnosis of severe infection. ${ }^{69}$ Serology and antigen testing can also be used for following response to treatment. A real-time PCR for 
coccidioidal DNA in respiratory secretions has recently been developed and initial testing shows 100\% sensitivity and 98\% specificity for the diagnosis of Coccidioides as compared to culture. Although not readily available everywhere, it may provide a rapid and safe way of diagnosis. ${ }^{70}$ In endemic areas for $C$. immitis, a chest radiograph and coccidioidal serologic tests for immunoglobulin $\mathrm{M}$ and immunoglobulin $\mathrm{G}$ should be considered before starting anti-TNF therapy to establish baseline. ${ }^{71}$ However, most cases of infection are acute rather than a reactivation, and these tests may be of limited value. ${ }^{71}$

Anti-TNF therapy should be discontinued whenever an invasive coccidioidal infection is identified. Treatment for pulmonary coccidioidomycosis is fluconazole (400-800 mg/day) for a period of 3-6 months. For severe systemic infections, treatment usually consists of amphotericin B deoxycholate $(0.5-1 \mathrm{mg} / \mathrm{kg} /$ day) until clinical improvement is achieved, followed by fluconazole (400-800 mg/day) for 12 months. ${ }^{72}$

\section{Candidiasis}

Candida spp are considered part of the normal flora of the gastrointestinal and genitourinary tracts of humans. However, in certain conditions such as disruption of the normal flora, a breach of the mucocutaneous barrier, or a defect in host cellular immunity, Candida can invade and cause disease. ${ }^{73}$ Candidiasis can present as a wide spectrum of disease ranging from local mucous membrane infections to widespread dissemination with multisystem organ failure. The gold standard for diagnosis is microscopic identification of the fungus from the infected site.

For mucocutaneous candidiasis topical antifungals such as nystatin applied two to three times daily is usually very effective. For disseminated or systemic infection, first-line treatment for Candida albicans is fluconazole (800 mg loading dose followed by $400 \mathrm{mg} /$ day) for $\geq 14$ days after last positive blood culture, or amphotericin B deoxycholate (0.5-1 $\mathrm{mg} / \mathrm{kg} /$ day) for $\geq 14$ days after last positive blood culture. ${ }^{6}$ Second-line treatment for resistant cases includes IV caspofungin, micafungin, or anidulafungin. ${ }^{6}$

\section{Aspergillosis}

Aspergillus spp are ubiquitous in nature and the spread of infection is usually by inhalation of infectious conidia, but rarely can occur through the gastrointestinal tract and direct skin inoculation. Aspergillosis can present in a variety of ways, causing respiratory tract diseases, cutaneous infection, or extrapulmonary dissemination. Pulmonary infection with cough, fever, dyspnea, and chest pain is the most common presentation. Disseminated disease is most frequently associated with immunocompromised states, as seen in patients with hematologic malignancies, hematopoietic cell transplantation, solid organ transplantation, or anti-TNF therapy. Signs and symptoms can be varied depending upon the organs involved. Chest radiographs are generally the first test obtained and may show nodules with surrounding ground glass infiltrates (halo sign). Diagnosis can be established by microscopic examination of respiratory secretions or BAL, serum antigen testing, and biopsy with culture.

The drug of choice for invasive infection is voriconazole beginning with a loading dose $(6 \mathrm{mg} / \mathrm{kg}$ every 12 hours for two doses) followed by maintenance doses ( $4 \mathrm{mg} / \mathrm{kg}$ every 12 hours) for $\geq 6-12$ weeks, or after resolution of symptoms. Alternatives include amphotericin B deoxycholate, posaconazole, itraconazole, and caspofungin.

\section{Cryptococcus}

Cryptococcus is an encapsulated fungus that has a worldwide distribution and is generally found in soil and in high concentrations near bird roosts. The organism is spread by inhalation after disruption of soil. Cryptococcosis is an invasive infection due to Cryptococcus neoformans or Cryptococcus gattii, and opportunistic infections by these pathogens have become increasingly more prevalent in immunocompromised patients. Although the presentation of cryptococcal infection can be varied, lung infection is most common. Other manifestations include fungemia, cutaneous infection, tenosynovitis, or CNS infection, especially meningitis. ${ }^{61}$ Diagnosis is established by antigen testing and cultures derived from involved tissues or fluid.

For mild to moderate pulmonary infections, treatment with fluconazole (400 mg/day) for 6-12 months is usually sufficient. For severe infections and CNS involvement, therapy consists of induction using liposomal amphotericin B (3-4 mg/kg/day IV) or amphotericin B lipid complex $(5 \mathrm{mg} / \mathrm{kg} /$ day IV) plus flucytosine $(100 \mathrm{mg} / \mathrm{kg} /$ day orally in four divided doses, adjusted for renal function) for $\geq 2$ weeks followed by fluconazole (400 mg/day) for 8 weeks. ${ }^{74}$

\section{PCP}

PCP is a nongranulomatous fungal infection caused by Pneumocystis jirovecii. The organism is spread via aerosol route and has the capacity to colonize the respiratory tract of asymptomatic individuals. ${ }^{75}$ Patients with impaired cellmediated immunity - as seen in AIDS, hematopoietic stem cell and solid organ transplant recipients, cancer patients (particularly hematologic malignancies), and patients on 
immunosuppressive medications (eg, glucocorticoids, chemotherapeutic agents) - are a higher risk for developing this infection. ${ }^{76}$ Patients contracting PCP in the absence of AIDS generally present with a more abrupt onset of respiratory insufficiency including fever, nonproductive cough, and progressive dyspnea. The rapid decline in respiratory status may correlate with a stronger inflammatory response, indicated by the presence of more neutrophils and lower numbers of Pneumocystis organisms in the lungs of such patients as compared to patients with AIDS. ${ }^{77,78}$ Typical radiographic findings include bilateral perihilar interstitial infiltrates that gradually become more homogenous. Other less common findings include nodules in the lungs, upper lobe infiltrates, and rarely pneumothorax. High resolution computed tomography scan is more sensitive than chest radiograph and may reveal extensive ground glass attenuation. $^{78}$

The gold standard for diagnosis is demonstration of the organism from BAL, induced sputum, or biopsy of the lung lesions. Pneumocystis cannot be cultured in vitro. ${ }^{78}$ PCR for Pneumocystis nucleic acid from BAL, blood, or nasopharyngeal aspirates, or $\beta$-D-glucan assay (a cell wall component) from the serum can also be used for initial screening. These tests have high sensitivity and specificity and are useful for rapid diagnosis, with the PCR test being used more frequently. ${ }^{78,79}$

The first-line treatment is trimethoprim-sulfamethoxazole (two double strength tablets three times daily) for $\geq 21$ days. For acutely ill patients with partial pressure of oxygen in arterial blood $<70 \mathrm{mmHg}$, trimethoprim-sulfamethoxazole is given (dose based on the trimethoprim component at $15 \mathrm{mg} / \mathrm{kg} /$ day IV) with prednisone (40 mg twice daily) for 5 days, usually followed by a tapering dose. ${ }^{78,80}$ Second-line treatment is either IV pentamidine, atovaquone, trimethoprim, and dapsone or pentamidine and clindamycin plus primaquine for 14-21 days. ${ }^{78}$ For those patients on triple immunomodulator therapy, with one of these being a calcineurin inhibitor or anti-TNF therapy, standard prophylaxis with trimethoprim-sulfamethoxazole $(80-400 \mathrm{mg})$ is recommended, if tolerated. For those on double immunomodulators, with one of these being a calcineurin inhibitor or anti-TNF therapy, prophylaxis can be considered but recommendations are still unclear. ${ }^{81}$

\section{Other fungal infections}

Other fungal infections that have been reported with anti-TNF therapy include zygomycetes, blastomycosis, mucormycosis, ${ }^{82}$ and sporotrichosis. ${ }^{83}$ These infections are rare among patients on anti-TNF therapy and information about their management remains limited.

\section{Viral infections}

TNF- $\alpha$, along with IFN- $\gamma$, plays a significant role in the immune response against viral infections. Inhibition of TNF- $\alpha$ can theoretically increase the risk of viral infections, but has only recently become an increased area of research. ${ }^{84}$ Some common viral infections associated with the use of anti-TNF therapy are described below and summarized in Tables 2 and 3 .

\section{HBV}

HBV is a member of the Hepadnaviridae family and has a worldwide prevalence of 350 million infected. ${ }^{85}$ Transmission occurs by parenteral, sexual, and perinatal routes. TNF- $\alpha$ and IFN- $\gamma$ synergistically inhibit the expression and replication of HBV genes, ${ }^{86}$ and TNF- $\alpha$ is also important for viral clearance. ${ }^{87}$ Anti-TNF therapy therefore carries a risk of viral reactivation, defined as either an increase of $>1 \log _{10}$ viral load, or $>2000$ copies/mL above the baseline HBV DNA load, or the appearance of serum HBV DNA above the standard cutoff values ( $>300$ copies $/ \mathrm{mL}){ }^{88}$ Reactivation has been observed in anti-TNF-treated patients who were hepatitis B surface antigen negative but hepatitis B core antibody positive ${ }^{89-93}$ this is probably related to the persistence of HBV DNA in the hepatocytes. ${ }^{94}$

The clinical manifestations of hepatitis $B$ reactivation range from asymptomatic to varying degrees of acute hepatitis leading to hepatic failure. ${ }^{95}$ Reactivation may occur during therapy or after the withdrawal of the anti-TNF therapy due to the reconstitution of the immune system. ${ }^{96}$ Because of the risk of reactivation, it is strongly recommended that patients' HBV status be identified before starting therapy. Therefore, ascertainment of hepatitis B surface antigen, anti-hepatitis B core antibody, and anti-hepatitis B surface antibody status should be determined in all patients - regardless of previous HBV history - to assess their infection and vaccination status. ${ }^{97}$ Viral DNA and liver biopsy may be indicated as well, depending on the serology results.

There is no standardized recommendation regarding chemoprophylaxis for HBV carriers planning to receive anti-TNF therapy. For patients with lower viral loads ( $<2000 \mathrm{IU} / \mathrm{mL}$ ), lamivudine beginning 2-4 weeks prior to the initiation of anti-TNF therapy and continued for $\geq 6$ months after cessation of therapy is recommended. ${ }^{98}$ This approach carries a high risk of development of lamivudine resistance if treatment is required for a longer course. ${ }^{99}$ Patients with HBV 
DNA levels $>2000 \mathrm{IU} / \mathrm{mL}$ should be treated for chronic hepatitis B as outlined by specific guidelines for HBV treatment. ${ }^{98}$ If a longer course of anti-TNF therapy is anticipated (ie, $>1$ year), which is usually the case in chronic inflammatory diseases, other nucleotide/nucleoside analogs such as tenofovir or entecavir should be considered. ${ }^{88,95,98}$ No chemoprophylaxis is currently recommended in anti-hepatitis B core antibody positive patients. Careful monitoring with viral tests and transaminases level, however, should be done every 1-3 months while the patient is on anti-TNF therapy. ${ }^{88}$ For those with active disease, HBV infection should be treated and controlled prior to the initiation of the anti-TNF therapy. ${ }^{88}$ $\mathrm{HBV}$ vaccination is an effective way to prevent infections and should be offered to all HBV-negative patients considering the use of anti-TNF agents. ${ }^{100}$

\section{Hepatitis C virus (HCV)}

$\mathrm{HCV}$, estimated to infect more than 200 million worldwide, ${ }^{101}$ is the leading cause of liver-related death in the US. ${ }^{102}$ The use of anti-TNF agents is safe and not associated with any significant change in viremia or liver function in patients infected with HCV. ${ }^{103-110}$ Etanercept has a synergetic effect when used in combination with recombinant IFN- $\alpha-2 b$ and ribavirin in a Phase II randomized double-blind placebo-controlled study, making the use of anti-TNF agents favorable when patients have a concomitant HCV infection. ${ }^{107}$

\section{Human immunodeficiency virus (HIV)}

HIV affects nearly 1.1 million people in the US. ${ }^{111}$ It is transmitted through parenteral, sexual, and perinatal routes. HIV-related mortality has declined dramatically since the introduction of antiretroviral therapy. ${ }^{112} \mathrm{TNF}-\alpha$ has been implicated in the pathogenesis of HIV infection by contributing to HIV replication through activation of nuclear factor- $\kappa \mathrm{B} .{ }^{113}$ Elevated levels of TNF- $\alpha$ are correlated to advanced stages of HIV infection and with opportunistic infections. ${ }^{114}$ Two small studies evaluating the safety of anti-TNF therapy in HIV patients failed to show any change in plasma HIV ribonucleic acid, cluster of differentiation-4+ lymphocyte count, or the occurrence of severe adverse effects. ${ }^{114,115}$ In conclusion, it appears the use of anti-TNF therapy in HIV patients is safe. Close monitoring of cluster of differentiation-4+ lymphocyte count and viral load with careful monitoring of clinical features of HIV and other infections is required. ${ }^{116}$

\section{Herpes simplex virus (HSV)}

HSV-1 and -2 are members of the Herpesviridae family. Primary infection with HSV in immunocompetent individuals usually causes an asymptomatic or mild self-limited orallabial (generally HSV-1) or genital (generally HSV-2) infection, followed by HSV persistence (latency) in nerve ganglia. ${ }^{117,118} \mathrm{HSV}$ reactivation in immunocompromised patients can lead to disseminated disease including encephalitis, meningitis, esophagitis, colitis, and hepatitis. ${ }^{119-121}$ Anti-TNF therapy is associated with increased risk of HSV reactivation and dissemination. ${ }^{122,123} \mathrm{HSV}$ colitis can mimic certain chronic inflammatory conditions such as acute exacerbation of IBD and has been associated with higher risk of colectomy. ${ }^{124}$ The gold standard method for diagnosing the infection is to detect the virus using PCR from infected tissues or body fluid. ${ }^{125}$

Acyclovir, valacyclovir, and famciclovir can be used for the treatment of acute or recurrent HSV infection. It is not recommended to use anti-TNF agents during the acute phase of HSV infection due to the increased risk of dissemination. Interruption of immunosuppression is recommended in patients with severe HSV infection. ${ }^{86}$

\section{VZV}

VZV belongs to the Herpesviridae family of viruses. Worldwide, up to $90 \%$ of adults demonstrate serologic evidence of prior infection with VZV. ${ }^{124}$ Infection is transmitted by close contact, most likely via the respiratory tract. ${ }^{98}$ TNF- $\alpha$ plays a significant role in the immune response against VZV as it blocks antigen expression and virus replication. Anti-TNF agents inhibit this antiviral activity, ${ }^{126}$ leading to severe viral infection. ${ }^{14} \mathrm{VZV}$ infection, unlike the other herpes virus infections, is usually symptomatic. ${ }^{124,127}$ It causes chickenpox in children (primary varicella) which is a mild self-limited disease; the primary infection then becomes latent, and in adults reactivation can occur and can cause shingles, which is manifested by painful skin vesicular lesions following a dermatomal distribution pattern. In immunocompromised patients, primary or reactivated infection can lead to more severe disseminated disease, such as hepatitis, pneumonia, encephalitis, and hemorrhagic complications. ${ }^{124,127}$ History of prior exposure is often not reliable; therefore VZV serology may need to be obtained in patients undergoing antiTNF therapy. Those who are seronegative can be offered the varicella vaccine. ${ }^{128}$ Serology has a limited value in diagnosing acute VZV infection; ${ }^{124}$ PCR, viral culture, and hybridization methods are more sensitive for confirming a diagnosis.

Several antiviral agents such as acyclovir, valacyclovir, and famciclovir can be used to treat acute VZV infection. Foscarnet as an alternative is recommended for resistant cases. ${ }^{124}$ Varicella vaccination is recommended in all children 
aged 12-18 months with a booster dose at 11-12 years of age. ${ }^{129}$ Varicella vaccine can also be offered to all adults without evidence of immunity to varicella prior to the initiation of immunosupression. Zoster vaccination has also been found to reduce the incidence of VZV by $50 \%$ and the risk of postherpetic neuralgia by $66 \%$ in people aged $>60$ years. ${ }^{127}$ It is recommended to administer the zoster vaccine to all of the immunocompetent persons aged $\geq 60$ years. ${ }^{130}$ Live varicella vaccine is contraindicated during anti-TNF therapy and should be administered $\geq 3$ weeks prior to the initiation of any immunosuppressant agent including anti-TNF agents.

\section{Epstein-Barr virus (EBV)}

EBV is also a member of the Herpesviridae family. It is transmitted by close contact through oral secretions. ${ }^{131}$ By adulthood, $90 \%-95 \%$ of people worldwide have been expected to have been exposed to the virus. ${ }^{132}$ Primary infection can be asymptomatic or can cause infectious mononucleosis in children and adolescents. ${ }^{131}$ Latent infection can be associated with different types of cancers and lymphoproliferative diseases. In transplant recipients receiving immunosuppressive therapy, $>80 \%$ of non-Hodgkin lymphomas are associated with EBV. ${ }^{133}$ Reports of EBV-associated lymphoproliferative disorder in patients on anti-TNF therapy have also been published. ${ }^{134,135}$ Diagnosis of the primary infection is usually suggested by clinical findings of infectious mononucleosis associated with atypical lymphocytosis on peripheral blood smear. ${ }^{132}$ Serologic tests measuring antibodies against specific viral antigens are useful in diagnosis, but real-time PCR may be more sensitive and reliable, especially in the early period of the EBV infection. ${ }^{136}$

Treatment is generally not required for infectious mononucleosis and supportive measures are adequate due to the self-limited nature of this illness. ${ }^{132}$ Antiviral therapy including acyclovir or ganciclovir can be used in more severe disease. Withdrawal of anti-TNF therapy should be considered in cases of severe EBV-associated disease. There is no commercially available vaccine for prevention and chemoprophylaxis is not recommended due to the insignificant risk imposed by anti-TNF therapy.

\section{Cytomegalovirus (CMV)}

CMV is a member of the Herpesviridae virus family, and is found and transmitted through body fluids. ${ }^{137}$ Seroprevalence studies suggest that $10 \%-20 \%$ of prepubescent children have been exposed to CMV and that this increases to $40 \%-100 \%$ in adults. ${ }^{138}$ Like other herpes viruses, the primary infection in immunocompetent patients is almost always asymptomatic, or it can present as a mononucleosis-like syndrome. ${ }^{139}$ Most CMV infections will become latent. In immunocompromised patients, there is a risk of reactivation of latent infection and the disease can involve nearly any organ. ${ }^{138}$ There have been several case reports of CMV reactivation causing severe infections after the initiation of anti-TNF therapy including disseminated disease, ${ }^{140}$ retinitis, ${ }^{141}$ colitis, ${ }^{142,143}$ hepatitis, ${ }^{144}$ and pneumonia. ${ }^{145}$

Although serology was found to be strongly associated with viremia, ${ }^{146}$ it has limited value in the diagnosis of an active infection in immunocompromised patients. ${ }^{147}$ Viral culture although highly specific - has limitations due to the prolonged incubation period, lack of viral quantitation, high false negativity, and low sensitivity compared with the antigenemia. ${ }^{147}$ PCR detection of viral DNA in blood is a fast and reliable method of early detection of viremia and has become widely used because of its high sensitivity and specificity. No screening is recommended for $\mathrm{CMV}$ in asymptomatic patients prior to starting anti-TNF therapy. A careful examination for end-organ manifestations of CMV infection prior to the initiation of the treatment is recommended. The CMV pp65 antigen level or the CMV DNA quantification should be performed in those who are symptomatic and suspected to have CMV infection.

For asymptomatic patients or those with mild disease, no therapy is indicated, and there is no contraindication to continuing the anti-TNF therapy. For patients with severe infection, immunomodulator therapy should be withheld and antiviral treatment instituted. ${ }^{141}$ Treatment options include ganciclovir ( $5 \mathrm{mg} / \mathrm{kg}$ IV twice daily) for 2-3 weeks; oral valganciclovir after 3-5 days can also be considered. Foscarnet ( $90 \mathrm{mg} / \mathrm{kg} \mathrm{IV}$ twice daily or $60 \mathrm{mg} / \mathrm{kg}$ IV three times daily) is an available alternative in cases of ganciclovir resistance or intolerance. Cessation of anti-TNF therapy is advised and can be resumed after the infection is resolved. ${ }^{148} \mathrm{CMV}$ colitis should be considered in the differential diagnosis of IBD exacerbation. Diagnosis should be ruled out, usually by performing a tissue PCR, in the steroid refractory disease before starting another immunosuppressive agent or prior to performing a colectomy.

\section{Human papillomavirus (HPV)}

HPV, a member of the Papillomaviridae family, is the most common sexually transmitted disease in the US. ${ }^{149}$ Several subtypes of HPV have been identified, but the most important subtypes are 16 and 18 which are associated with $70 \%$ of HPV-associated cervical cancers. ${ }^{150}$ The risk of HPVassociated cancers increases with the use of immunosuppressant agents such as anti-TNF agents. ${ }^{151,152}$ Low-risk subtypes (eg, 1, 2, 4, 6, 11) cause skin warts, while the highrisk strains (eg, 16, 18, 30, 31) are associated with cervical 
dysplasia, cervical cancer, rectal carcinoma, and penile, vulvar, vaginal, and oropharyngeal carcinomas. ${ }^{153}$

The majority of HPV infections are silent and asymptomatic, and the virus is usually cleared as a result of cellular immune responses within 1 year. ${ }^{102}$ Multiple factors are associated with increased risk, such as age (with highest risk between 35-55 years), cigarette smoking, use of contraceptives, family history, and coexistence of other infections such as HIV. ${ }^{142}$ Cervical screening with Pap smears is recommended annually for younger women ( $<30$ years) and every $2-3$ years for older women ( $>30$ years) who have had three consecutive annual negative Pap smears. Screening should begin at 21 years of age, or within 3 years of beginning sexual activity.

No systemic antiviral therapy is indicated for patients with HPV infection. Treatment of complications, including dysplasia and cancer, include surgery, chemotherapy and radiotherapy. ${ }^{154}$ Primary prevention through vaccination is recommended for all females $>11$ years old; secondary prevention is by regular cervical screening. Recent studies recommend the HPV vaccine for males to prevent HPVassociated penile carcinoma.

\section{Parasitic infections}

Parasitic infections often cause significant morbidity and mortality in immunocompromised patients. ${ }^{153}$ Only a few case reports are available describing these infections in patients receiving anti-TNF therapy. ${ }^{155}$ Some common parasitic infections associated with the use of anti-TNF therapy are described below and summarized in Tables 2 and 3.

\section{Toxoplasma}

Toxoplasma gondii, an intracellular protozoan that causes toxoplasmosis, is well described in HIV-positive patients. ${ }^{156}$ Felines are the primary host of this protozoan and $T$. gondii oocytes pass with the animal's stool and cause toxoplasmosis if ingested by humans. TNF- $\alpha$ and IFN- $\gamma$ synergistically inhibit the growth of $T$. gondii. ${ }^{157}$ In an immunocompetent host, the primary infection is asymptomatic in $90 \%$ of cases. To date, only a few cases of toxoplasmosis in patients receiving anti-TNF agents have been reported, including cases of cerebral toxoplasmosis and chorioretinitis in patients who were treated with either etanercept or infliximab. ${ }^{158-160}$ Diagnosis of toxoplasmosis is usually accomplished by serologic assays, including enzyme-linked immunosorbent assay and detection of the organism's DNA using PCR from blood, CSF, or amniotic fluid. ${ }^{161}$
The first-line treatment consists of 6 weeks of sulfadiazine (1.0-1.5 g orally every 6 hours) with pyrimethamine (100-200 mg orally loading dose, then $50 \mathrm{mg}$ orally once daily) and folinic acid (10-20 mg orally once daily). ${ }^{162} \mathrm{In}$ patients allergic to sulfa drugs, the sulfadiazine may be substituted by atovaquone or clindamycin. Infection with toxoplasma can be prevented by consuming properly cooked meat, avoiding close contact with stray cats, avoiding contaminated soil and/or water, and avoiding unscreened blood transfusions. No preventive vaccine is commercially available.

\section{Strongyloides}

Strongyloidiasis, caused most commonly by Strongyloides stercoralis, is endemic in tropical and subtropical regions with prevalence rates reaching up to $25 \%$ in Central America, Latin America, Africa, and Southeast Asia. ${ }^{163}$ Infection occurs either through the penetration of the skin or through an autoinfection by intestinal mucosa penetration in previously infected patients. Strongyloides infection, which can be asymptomatic in $30 \%$ of cases, usually presents with cutaneous, gastrointestinal, or pulmonary symptoms. In immunocompromised patients, it can also cause accelerated autoinfection called hyperinfection syndrome or disseminated infection. The diagnosis of disseminated infection is confirmed by direct identification of Strongyloides rhabditiform larvae from different clinical specimens: stool, sputum, serum/blood smears, bronchial aspirates, CSF, peritoneal fluid, or ascitic fluid. ${ }^{164}$ Serology with enzyme-linked immunosorbent assay can be performed if Strongyloides infection is suspected and larvae cannot be detected. ${ }^{165}$

Ivermectin $(200 \mu \mathrm{g} / \mathrm{kg} /$ day $)$ for 2 days is the treatment of choice for immunocompetent patients with chronic asymptomatic Strongyloides infection. If hyperinfection syndrome or disseminated infection develop, the same treatment should be continued for $\geq 7-10$ days, or until the clinical symptoms are resolved. ${ }^{166}$ Chemoprophylaxis with ivermectin to prevent hyperinfection syndrome or disseminated infection is recommended in immunocompromised individuals who are a confirmed asymptomatic chronic carrier, including those receiving anti-TNF therapy. ${ }^{167}$

\section{Leishmania}

Leishmaniasis is caused by heterogeneous group of Leishmania spp, which are intracellular protozoan parasites. Global epidemiological surveillance has shown that Leishmania infections affect more than 12 million people worldwide, and 2 million new cases are reported annually. ${ }^{168}$ Clinically, two basic forms are recognized: cutaneous 
leishmaniasis, a disfiguring and stigmatizing disease, and visceral leishmaniasis or kala-azar, a life-threatening but treatable condition if diagnosed early. TNF- $\alpha$ has a major role in mediating host protection against visceral leishmaniasis, ${ }^{169}$ so the use of anti-TNF agents may potentially cause worsening or reactivation of latent infection. ${ }^{169}$ Four case reports of visceral leishmaniasis occurring in rheumatoid arthritis patients treated with infliximab have been published. ${ }^{169-172}$ Diagnosis is made by the detection of the parasite in bone marrow or blood, or by PCR assays performed on blood and bone marrow. ${ }^{171}$

Antileishmanial therapy consists of antimonial compounds (sodium stibogluconate and meglumine antimoniate), miltefosine, and amphotericin B. Liposomal amphotericin B $(3.0 \mathrm{mg} / \mathrm{kg})$ is the drug of choice for treatment of visceral leishmaniasis. ${ }^{173}$

\section{Other parasitic infections}

Giardia intestinalis is a common pathogenic intestinal parasite of humans that causes acute and chronic diarrhea. Cryptosporidium spp are also common parasites, causing significant mortality and morbidity worldwide, especially among immunocompromised patients. ${ }^{174}$ However, no increased risk of these parasitic infections associated with use of anti-TNF therapy was found.

\section{Conclusion}

Biological therapies targeting TNF- $\alpha$ represent a revolution in the treatment of chronic inflammatory diseases, especially in cases refractory to conventional treatment modalities. They offer significant benefits in disease control and improving quality of life. As anti-TNF blockers are increasingly used in the management of these illnesses, their adverse effects, risk versus benefit analysis, and patient individualization of treatment options must be considered. Patients must be advised about the risk of infections, malignancies, and various other potential adverse effects of anti-TNF therapy.

\section{Disclosure}

The authors report no conflicts of interest in this work.

\section{References}

1. Van Deventer SJ. Tumour necrosis factor and Crohn's disease. Gut. 1997;40(4):443-448.

2. Shim H. One target, different effects: a comparison of distinct therapeutic antibodies against the same targets. Exp Mol Med.2011;43(10):539-549.

3. Brennan FM, Maini RN, Feldmann M. TNF alpha - a pivotal role in rheumatoid arthritis? Br J Rheumatol. 1992;31(5):293-298.

4. Maini RN, Feldmann M. How does infliximab work in rheumatoid arthritis? Arthritis Res. 2002;4(Suppl 2):S22-S28.
5. Koo S, Marty FM, Baden LR. Infectious complications associated with immunomodulating biologic agents. Infect Dis Clin North Am. 2010;24(2):285-306.

6. Roach DR, Bean AG, Demangel C, France MP, Briscoe H, Britton WJ. TNF regulates chemokine induction essential for cell recruitment, granuloma formation, and clearance of mycobacterial infection. $J$ Immunol. 2002;168(9):4620-4627.

7. Symmers WS. Opportunistic infections. The concept of "opportunistic infections." Proc R Soc Med. 1965;58:341-346.

8. Chandra RK. Nutrition, immunity and infection: from basic knowledge of dietary manipulation of immune responses to practical application of ameliorating suffering and improving survival. Proc Natl Acad Sci U S A. 1996;93(25):14304-14307.

9. Toruner M, Loftus EV Jr, Harmsen WS, et al. Risk factors for opportunistic infections in patients with inflammatory bowel disease. Gastroenterology. 2008;134(4):929-936.

10. Krok KL, Lichtenstein GR. Nutrition in Crohn disease. Curr Opin Gastroenterol. 2003;19(2):148-153.

11. Rahier JF, Ben-Horin S, Chowers Y, et al. European evidence-based consensus on the prevention, diagnosis and management of opportunistic infections in inflammatory bowel disease. J Crohns Colitis. 2009;3(2):47-91.

12. Wallis RS, Broder M, Wong J, Lee A, Hoq L. Reactivation of latent granulomatous infections by infliximab. Clin Infect Dis. 2005; 41(Suppl 3):S194-S198.

13. Carroll MB, Forgione MA. Use of tumor necrosis factor alpha inhibitors in hepatitis B surface antigen-positive patients: a literature review and potential mechanisms of action. Clin Rheumatol. 2010;29(9): 1021-1029.

14. Strangfeld A, Listing J, Herzer P, et al. Risk of herpes zoster in patients with rheumatoid arthritis treated with anti-TNF-alpha agents. JAMA. 2009;301(7):737-744.

15. Centers for Disease Control and Prevention. Trends in tuberculosis - United States, 2011. MMWR Morb Mortal Wkly Rep. 2012;61(11):181-185.

16. Solovic I, Sester M, Gomez-Reino JJ, et al. The risk of tuberculosis related to tumour necrosis factor antagonist therapies: a TBNET consensus statement. Eur Respir J. 2010;36(5):1185-1206.

17. British Thoracic Society Standards of Care Committee. BTS recommendations for assessing risk and for managing Mycobacterium tuberculosis infection and disease in patients due to start anti-TNF-alpha treatment. Thorax. 2005;60(10):800-805.

18. Keane J, Gershon S, Wise RP, et al. Tuberculosis associated with infliximab, a tumor necrosis factor alpha-neutralizing agent. New Engl J Med. 2001;345(15):1098-1104.

19. Greenaway C, Sandoe A, Vissandjee B, et al. Tuberculosis: evidence review for newly arriving immigrants and refugees. CMAJ. 2011; 183(12):E939-E951.

20. Davies PDO, Chakrabarti B, Albert P. Latest developments in diagnosis of tuberculosis. Eur Infect Dis. 2009;2(2):75-76.

21. Pai M, Joshi R, Dogra S, et al. Serial testing of health care workers for tuberculosis using interferon-gamma assay. Am J Respir Crit Care Med. 2006;174(3):349-355.

22. Hecker MT, Johnson JL, Whalen CC, Nyole S, Mugerwa RD, Ellner JJ. Two-step tuberculin skin testing in HIV-infected persons in Uganda. Am J Respir Crit Care Med. 1997;155(1):81-86.

23. Joint Tuberculosis Committee of the British Thoracic Society. Chemotherapy and management of tuberculosis in the United Kingdom: recommendations 1998. Thorax. 1998;53(7):536-548.

24. Fuchs I, Avnon L, Freud T, Abu-Shakra M. Repeated tuberculin skin testing following therapy with TNF-alpha inhibitors. Clin Rheumatol. 2009;28(2):167-172.

25. Ananthakrishnan AN, McGinley EL, Binion DG. Excess hospitalisation burden associated with Clostridium difficile in patients with inflammatory bowel disease. Gut. 2008;57(2):205-210.

26. Ananthakrishnan AN. Detecting and treating Clostridium difficile infections in patients with inflammatory bowel disease. Gastroenterol Clin North Am. 2012;41(2):339-353. 
27. Sinh P, Barrett TA, Yun L. Clostridium difficile infection and inflammatory bowel disease: a review. Gastroenterol Res Pract. 2011;2011:136064.

28. Wanahita A, Goldsmith EA, Marino BJ, Musher DM. Clostridium difficile infection in patients with unexplained leukocytosis. $\mathrm{Am} \mathrm{J} \mathrm{Med.}$ 2003;115(7):543-546.

29. Peterson LR, Manson RU, Paule SM, et al. Detection of toxigenic Clostridium difficile in stool samples by real-time polymerase chain reaction for the diagnosis of C. difficile-associated diarrhea. Clin Infect Dis. 2007;45(9):1152-1160.

30. Cohen SH, Gerding DN, Johnson S, et al. Clinical practice guidelines for Clostridium difficile infection in adults: 2010 update by the Society for Healthcare Epidemiology of America (SHEA) and the Infectious Diseases Society of America (IDSA). Infect Control Hosp Epidemiol. 2010;31(5):431-455.

31. Louie TJ, Miller MA, Mullane KM, et al. Fidaxomicin versus vancomycin for Clostridium difficile infection. New Engl J Med. 2011; 364(5):422-431.

32. Johnson S, Schriever C, Galang M, Kelly CP, Gerding DN. Interruption of recurrent Clostridium difficile-associated diarrhea episodes by serial therapy with vancomycin and rifaximin. Clin Infect Dis. 2007;44(6): 846-848.

33. Butala P, Divino CM. Surgical aspects of fulminant Clostridium difficile colitis. Am J Surg. 2010;200(1):131-135.

34. Greenstein AJ, Byrn JC, Zhang LP, Swedish KA, Jahn AE, Divino CM. Risk factors for the development of fulminant Clostridium difficile colitis. Surgery. 2008;143(5):623-629.

35. Bakken JS. Fecal bacteriotherapy for recurrent Clostridium difficile infection. Anaerobe. 2009;15(6):285-289.

36. Gough E, Shaikh H, Manges AR. Systematic review of intestinal microbiota transplantation (fecal bacteriotherapy) for recurrent Clostridium difficile infection. Clin Infect Dis. 2011;53(10):994-1002.

37. Chan AT, Cleeve V, Daymond TJ. Necrotising fasciitis in a patient receiving infliximab for rheumatoid arthritis. Postgrad Med J. 2002;78(915):47-48.

38. Mandell LA, Wunderink RG, Anzueto A, et al. Infectious Diseases Society of America/American Thoracic Society consensus guidelines on the management of community-acquired pneumonia in adults. Clin Infect Dis. 2007;4(Suppl 2):S27-S72.

39. Tunkel AR, Hartman BJ, Kaplan SL, et al. Practice guidelines for the management of bacterial meningitis. Clin Infect Dis. 2004;39(9): $1267-1284$

40. Centers for Disease Control and Prevention. Use of 13-valent pneumococcal conjugate vaccine and 23-valent pneumococcal polysaccharide vaccine for adults with immunocompromising conditions: recommendations of the Advisory Committee on Immunization Practices (ACIP). MMWR Morb Mortal Wkly Rep. 2012;61(40):816-819.

41. Fiorino G, Peyrin-Biroulet L, Naccarato P, et al. Effects of immunosuppression on immune response to pneumococcal vaccine in inflammatory bowel disease: a prospective study. Inflamm Bowel Dis. 2012;18(6):1042-1047.

42. Diederen BM. Legionella spp and Legionnaires' disease. $J$ Infect. 2008;56(1):1-12.

43. Glick TH, Gregg MB, Berman B, Mallison G, Rhodes WW Jr, Kassanoff I. Pontiac fever. An epidemic of unknown etiology in a health department: I. Clinical and epidemiologic aspects. Am J Epidemiol. 1978;107(2):149-160.

44. Yu VL, Greenberg RN, Zadeikis N, et al. Levofloxacin efficacy in the treatment of community-acquired legionellosis. Chest. 2004; 125(6):2135-2139.

45. FDA drug safety communication: drug labels for tumor necrosis factor-alpha (TNF $\alpha)$ blockers now include warnings about infections with Legionella and Listeria bacteria [webpage on the Internet]. Silver Spring, MD: US Food and Drug Administration; 2011. Available from: http://www.fda.gov/drugs/drugsafety/ucm270849.htm. Accessed February 13, 2013.

46. Wing EJ, Gregory SH. Listeria monocytogenes: clinical and experimental update. J Infect Dis. 2002;185(Suppl 1):S18-S24.
47. Wallis RS, Broder MS, Wong JY, Hanson ME, Beenhouwer DO. Granulomatous infectious diseases associated with tumor necrosis factor antagonists. Clin Infect Dis. 2004;38(9):1261-1265.

48. Lorber B. Listeriosis. Clin Infect Dis. 1997;24(1):1-9.

49. Mylonakis E, Hohmann EL, Calderwood SB. Central nervous system infection with Listeria monocytogenes. 33 years' experience at a general hospital and review of 776 episodes from the literature. Medicine (Baltimore). 1998;77(5):313-336.

50. Food safety: foodborne illness, foodborne disease (sometimes called "food poisoning") [webpage on the Internet]. Atlanta, GA: Centers for Disease Control and Prevention; 2011. Available from: http://www.cdc. gov/foodsafety/facts.html. Accessed February 13, 2013.

51. Gordon MA. Salmonella infections in immunocompromised adults. J Infect. 2008;56(6):413-422.

52. Gilbert DN, Moellering RC, Eliopoulos GM, Sande MA. The Sandford Guide to Antimicrobial Therapy 2006, 36th ed. Sperryville, VA: Antimicrobial Therapy; 2006.

53. Dryden MS, Gabb RJ, Wright SK. Empirical treatment of severe acute community-acquired gastroenteritis with ciprofloxacin. Clin Infect Dis. 1996;22(6):1019-1025.

54. Goodman LJ, Trenholme GM, Kaplan RL, et al. Empiric antimicrobial therapy of domestically acquired acute diarrhea in urban adults. Arch Intern Med. 1990;150(3):541-546.

55. National center for emerging zoonotic infectious diseases. Available from: http://www.cdc.gov/nocardiosis/infection/index.html. Accessed Jan 28, 2013.

56. Wilson JW. Nocardiosis: updates and clinical overview. Mayo Clin Proc. 2012;87(4):403-407.

57. Simpson GL, Stinson EB, Egger MJ, Remington JS. Nocardial infections in the immunocompromised host: a detailed study in a defined population. Rev Infect Dis. 1981;3(3):492-507.

58. Smith JA, Kauffman CA. Endemic fungal infections in patients receiving tumour necrosis factor-alpha inhibitor therapy. Drugs. 2009;69(11):1403-1415.

59. Chu JH, Feudtner C, Heydon K, Walsh TJ, Zaoutis TE. Hospitalizations for endemic mycoses: a population-based national study. Clin Infect Dis. 2006;42(6):822-825.

60. Goodwin RA Jr, Shapiro JL, Thurman GH, Thurman SS, Des Prez RM. Disseminated histoplasmosis: clinical and pathologic correlations. Medicine (Baltimore). 1980;59(1):1-33.

61. Arnold TM, Sears CR, Hage CA. Invasive fungal infections in the era of biologics. Clin Chest Med. 2009;30(2):279-286.

62. Hage CA, Bowyer S, Tarvin SE, Helper D, Kleiman MB, Wheat LJ. Recognition, diagnosis, and treatment of histoplasmosis complicating tumor necrosis factor blocker therapy. Clin Infect Dis. 2010;50(1): $85-92$.

63. Wood KL, Hage CA, Knox KS, et al. Histoplasmosis after treatment with anti-tumor necrosis factor-alpha therapy. Am J Respir Crit Care Med. 2003;167(9):1279-1282.

64. Information for healthcare professionals: Cimzia (certolizumab pegol), Enbrel (etanercept) Humira (adalimumab) and Remicade (infliximab) [webpage on the Internet]. Silver Spring, MD: US Food and Drug Administration; 2010. Available from: http://www.fda.gov/drugs/ drugsafety/postmarketdrugsafetyinformationforpatientsandproviders/ ucm124185.htm. Accessed October 6, 2011.

65. Wheat LJ, Freifeld AG, Kleiman MB, et al. Clinical practice guidelines for the management of patients with histoplasmosis: 2007 update by the Infectious Diseases Society of America. Clin Infect Dis. 2007; 45(7):807-825.

66. Wheat LJ, Cloud G, Johnson PC, et al. Clearance of fungal burden during treatment of disseminated histoplasmosis with liposomal amphotericin B versus itraconazole. Antimicrob Agents Chemother. 2001;45(8):2354-2357.

67. Hage CA, Kirsch EJ, Stump TE, et al. Histoplasma antigen clearance during treatment of histoplasmosis in patients with AIDS determined by a quantitative antigen enzyme immunoassay. Clin Vaccine Immunol. 2011;18(4):661-666. 
68. Wheat LJ, Batteiger BE, Sathapatayavongs B. Histoplasma capsulatum infections of the central nervous system. A clinical review. Medicine (Baltimore). 1990;69(4):244-260.

69. Durkin M, Connolly P, Kuberski T, et al. Diagnosis of coccidioidomycosis with use of the Coccidioides antigen enzyme immunoassay. Clin Infect Dis. 2008;47(8):e69-e73.

70. Singh VR, Smith DK, Lawerence J, et al. Coccidioidomycosis in patients infected with human immunodeficiency virus: review of 91 cases at a single institution. Clin Infect Dis. 1996;23(3): 563-568.

71. Bergstrom L, Yocum DE, Ampel NM, et al. Increased risk of coccidioidomycosis in patients treated with tumor necrosis factor alpha antagonists. Arthritis Rheum. 2004;50(6):1959-1966.

72. Galgiani JN, Ampel NM, Blair JE, et al. Coccidioidomycosis. Clin Infect Dis. 2005;41(9):1217-1223.

73. Naglik JR, Challacombe SJ, Hube B. Candida albicans secreted aspartyl proteinases in virulence and pathogenesis. Microbiol Mol Biol Rev. 2003;67(3):400-428.

74. Perfect JR, Dismukes WE, Dromer F, et al. Clinical practice guidelines for the management of cryptococcal disease: 2010 update by the Infectious Diseases Society of America. Clin Infect Dis. 2010;50(3): 291-322.

75. Davis JL, Welsh DA, Beard CB, et al. Pneumocystis colonisation is common among hospitalised HIV infected patients with non-pneumocystis pneumonia. Thorax. 2008;63(4):329-334.

76. Sepkowitz KA. Opportunistic infections in patients with and patients without acquired immunodeficiency syndrome. Clin Infect Dis. 2002; 34(8):1098-1107.

77. Kales CP, Murren JR, Torres RA, Crocco JA. Early predictors of in-hospital mortality for Pneumocystis carinii pneumonia in the acquired immunodeficiency syndrome. Arch Intern Med. 1987;147(8): 1413-1417.

78. Thomas CF Jr, Limper AH. Pneumocystis pneumonia. New Engl J Med. 2004;350(24):2487-2498.

79. Tasaka S, Hasegawa N, Kobayashi S, et al. Serum indicators for the diagnosis of pneumocystis pneumonia. Chest. 2007;131(4): 1173-1180.

80. Hughes WT, Feldman S, Sanyal SK. Treatment of Pneumocystis carinii pneumonitis with trimethoprim-sulfamethoxazole. Can Med Assoc J. 1975;112(13 Spec No):47-50.

81. Rodriguez M, Fishman JA. Prevention of infection due to Pneumocystis spp. in human immunodeficiency virus-negative immunocompromised patients. Clin Microbiol Rev. 2004;17(4):770-782.

82. Morton J, Nguyen V, Ali T. Mucormycosis of the intestine: a rare complication in Crohn's disease. Gastroenterol Hepatol (N Y). 2012;8(2): 137-140.

83. Gottlieb GS, Lesser CF, Holmes KK, Wald A. Disseminated sporotrichosis associated with treatment with immunosuppressants and tumor necrosis factor-alpha antagonists. Clin Infect Dis. 2003;37(6): 838-840.

84. Tracey D, Klareskog L, Sasso EH, Salfeld JG, Tak PP. Tumor necrosis factor antagonist mechanisms of action: a comprehensive review. Pharmacol Ther. 2008;117(2):244-279.

85. Lavanchy D. Hepatitis B virus epidemiology, disease burden, treatment, and current and emerging prevention and control measures. J Viral Hepat. 2004;11(2):97-107.

86. Domm S, Cinatl J, Mrowietz U. The impact of treatment with tumour necrosis factor-alpha antagonists on the course of chronic viral infections: a review of the literature. Br J Dermatol. 2008;159(6):1217-1228.

87. Ostuni P, Botsios C, Punzi L, Sfriso P, Todesco S. Hepatitis B reactivation in a chronic hepatitis B surface antigen carrier with rheumatoid arthritis treated with infliximab and low dose methotrexate. Ann Rheum Dis. 2003;62(7):686-687.

88. Perez-Alvarez R, Diaz-Lagares C, Garcia-Hernandez F, et al. Hepatitis $B$ virus (HBV) reactivation in patients receiving tumor necrosis factor (TNF)-targeted therapy: analysis of 257 cases. Medicine (Baltimore). 2011;90(6):359-371.
89. Matsumoto T, Marusawa H, Dogaki M, Suginoshita Y, Inokuma T. Adalimumab-induced lethal hepatitis B virus reactivation in an HBsAgnegative patient with clinically resolved hepatitis B infection. Liver Int. 2010;30(8):1241-1242.

90. Millonig G, Kern M, Ludwiczek O, Nachbaur K, Vogel W. Subfulminant hepatitis B after infliximab in Crohn's disease: need for HBVscreening. World J Gastroenterol. 2006;12(6):974-976.

91. Montiel PM, Solis JA, Chirinos JA, Casis B, Sanchez F, Rodriguez S. Hepatitis B virus reactivation during therapy with etanercept in an HBsAg-negative and anti-HBs-positive patient. Liver Int. 2008;28(5): $718-720$.

92. Michel M, Duvoux C, Hezode C, Cherqui D. Fulminant hepatitis after infliximab in a patient with hepatitis $\mathrm{B}$ virus treated for an adult onset still's disease. J Rheumatol. 2003;30(7):1624-1625.

93. Madonia S, Orlando A, Scimeca D, Olivo M, Rossi F, Cottone M. Occult hepatitis B and infliximab-induced HBV reactivation. Inflamm Bowel Dis. 2007;13(4):508-509.

94. Zoulim F. New insight on hepatitis B virus persistence from the study of intrahepatic viral cccDNA. J Hepatol. 2005;42(3):302-308.

95. Manzano-Alonso ML, Castellano-Tortajada G. Reactivation of hepatitis $B$ virus infection after cytotoxic chemotherapy or immunosuppressive therapy. World J Gastroenterol. 2011;17(12):1531-1537.

96. Carroll MB, Bond MI. Use of tumor necrosis factor-alpha inhibitors in patients with chronic hepatitis B infection. Semin Arthritis Rheum. 2008;38(3):208-217.

97. Lok AS, McMahon BJ. Chronic hepatitis B: update 2009. Hepatology. 2009;50(3):661-662.

98. Ali T, Yun L, Shapiro D, Madhoun MF, Bronze M. Viral infections in patients with inflammatory bowel disease on immunosuppressants Am J Med Sci. 2012;343(3):227-232.

99. Chotiyaputta W, Lok AS. Hepatitis B virus variants. Nat Rev Gastroenterol Hepatol. 2009;6(8):453-462.

100. Nathan DM, Angus PW, Gibson PR. Hepatitis B and C virus infections and anti-tumor necrosis factor-alpha therapy: guidelines for clinical approach. J Gastroenterol Hepatol. 2006;21(9):1366-1371.

101. Lavency D, McMahon B. Worldwide prevalence and prevention of hepatitis C. In: Liang TJ, Hoofnagle JH, editors. Hepatitis C. San Diego, CA: Academic Press; 2000:185-201.

102. Kim WR. The burden of hepatitis $\mathrm{C}$ in the United States. Hepatology. 2002;36(5 Suppl 1):S30-S34.

103. Cansu DU, Kalifoglu T, Korkmaz C. Short-term course of chronic hepatitis $\mathrm{B}$ and $\mathrm{C}$ under treatment with etanercept associated with different disease modifying antirheumatic drugs without antiviral prophylaxis. J Rheumatol. 2008;35(3):421-424.

104. Aslanidis S, Vassiliadis T, Pyrpasopoulou A, Douloumpakas I, Zamboulis C. Inhibition of TNFalpha does not induce viral reactivation in patients with chronic hepatitis $\mathrm{C}$ infection: two cases. Clin Rheumatol. 2007;26(2):261-264.

105. De Simone C, Paradisi A, Capizzi R, Carbone A, Siciliano M, Amerio PL. Etanercept therapy in two patients with psoriasis and concomitant hepatitis C. J Am Acad Dermatol. 2006;54(6):1102-1104.

106. Rokhsar C, Rabhan N, Cohen SR. Etanercept monotherapy for a patient with psoriasis, psoriatic arthritis, and concomitant hepatitis $\mathrm{C}$ infection. J Am Acad Dermatol. 2006;54(2):361-362.

107. Magliocco MA, Gottlieb AB. Etanercept therapy for patients with psoriatic arthritis and concurrent hepatitis $\mathrm{C}$ virus infection: report of 3 cases. J Am Acad Dermatol. 2004;51(4):580-584.

108. Marotte H, Fontanges E, Bailly F, Zoulim F, Trepo C, Miossec P. Etanercept treatment for three months is safe in patients with rheumatological manifestations associated with hepatitis C virus. Rheumatology (Oxford). 2007;46(1):97-99.

109. Cecchi R, Bartoli L. Psoriasis and hepatitis $C$ treated with anti-TNF alpha therapy (etanercept). Dermatol Online J. 2006;12(7):4.

110. Peterson JR, Hsu FC, Simkin PA, Wener MH. Effect of tumour necrosis factor alpha antagonists on serum transaminases and viraemia in patients with rheumatoid arthritis and chronic hepatitis $\mathrm{C}$ infection. Ann Rheum Dis. 2003;62(11):1078-1082. 
111. Hopkins RS, Jajosky RA, Hall PA, et al. Summary of notifiable diseases - United States, 2003. MMWR Morb Mortal Wkly Rep. 2005; 52(54):1-85.

112. Palella FJ Jr, Delaney KM, Moorman AC, et al; HIV Outpatient Study Investigators. Declining morbidity and mortality among patients with advanced human immunodeficiency virus infection. New Engl J Med. 1998;338(13):853-860.

113. Duh EJ, Maury WJ, Folks TM, Fauci AS, Rabson AB. Tumor necrosis factor alpha activates human immunodeficiency virus type 1 through induction of nuclear factor binding to the NF-kappa B sites in the long terminal repeat. Proc Natl Acad Sci U SA. 1989;86(15):5974-5978.

114. Habib SF, Hasan MZ, Salam I. Infliximab therapy for HIV positive Crohn's disease: a case report. J Crohns Colitis. 2009;3(4): 302-304.

115. Walker RE, Spooner KM, Kelly G, et al. Inhibition of immunoreactive tumor necrosis factor-alpha by a chimeric antibody in patients affected with human immunodeficiency virus type 1. J Infect Dis. 1996;174(1):63-68.

116. Sha BE, Valdez H, Gelman RS, et al. Effect of etanercept (Enbrel) on interleukin 6, tumor necrosis factor alpha, and markers of immune activation in HIV-infected subjects receiving interleukin 2. AIDS Res Human Retroviruses. 2002;18(9):661-665.

117. Kalantari-Dehaghi M, Chun S, Chentoufi AA, et al. Discovery of potential diagnostic and vaccine antigens in herpes simplex virus 1 and 2 by proteome-wide antibody profiling. J Virol. 2012;86(8):4328-4339.

118. Gupta R, Warren T, Wald A. Genital herpes. Lancet. 2007; 370(9605):2127-2137.

119. el-Serag HB, Zwas FR, Cirillo NW, Eisen RN. Fulminant herpes colitis in a patient with Crohn's disease. J Clin Gastroenterol. 1996;22(3):220-223.

120. Wolfsen HC, Bolen JW, Bowen JL, Fenster LF. Fulminant herpes hepatitis mimicking hepatic abscesses. $J$ Clin Gastroenterol. 1993;16(1):61-64.

121. Taplitz RA, Jordan MC. Pneumonia caused by herpesviruses in recipients of hematopoietic cell. Semin Respir Infect. 2002;17(2):121-129.

122. Justice EA, Khan SY, Logan S, Jobanputra P. Disseminated cutaneous herpes simplex virus-1 in a woman with rheumatoid arthritis receiving infliximab: a case report. J Med Case Rep. 2008;2:282.

123. Bradford RD, Pettit AC, Wright PW, et al. Herpes simplex encephalitis during treatment with tumor necrosis factor-alpha inhibitors. Clin Infect Dis. 2009;49(6):924-927.

124. Arvin AM. Varicella-zoster virus. Clin Microbiol Rev. 1996; 9(3):361-381.

125. Shenoy ES, Mylonakis E, Hurtado RM, Venna N. Natalizumab and HSV meningitis. J Neurovirol. 2011;17(3):288-290.

126. Ito M, Nakano T, Kamiya T, et al. Effects of tumor necrosis factor alpha on replication of varicella-zoster virus. Antiviral Res. 1991;15(3):183-192.

127. Hambleton S, Gershon AA. Preventing varicella-zoster disease. Clin Microbiol Rev. 2005;18(1):70-80.

128. Kopylov U, Levin A, Mendelson E, et al. Prior varicella zoster virus exposure in IBD patients treated by anti-TNFs and other immunomodulators: implications for serological testing and vaccination guidelines. Alimentary Pharmacol Ther. 2012;36(2):145-150.

129. Marin M, Guris D, Chaves SS, Schmid S, Seward JF. Prevention of varicella: recommendations of the Advisory Committee on Immunization Practices (ACIP). MMWR Recomm Rep. 2007;56(RR-4):1-40.

130. Harpaz R, Ortega-Sanchez IR, Seward JF. Prevention of herpes zoster: recommendations of the Advisory Committee on Immunization Practices (ACIP). MMWR Recomm Rep. 2008;57(RR-5):1-30.

131. Cohen JI. Epstein-Barr virus infection. New Engl J Med. 2000; 343(7):481-492.

132. Luzuriaga K, Sullivan JL. Infectious mononucleosis. $N$ Engl J Med. 2010;362(21):1993-2000.

133. Reijasse D, Le Pendeven C, Cosnes J, et al. Epstein-Barr virus viral load in Crohn's disease: effect of immunosuppressive therapy. Inflamm Bowel Dis. 2004;10(2):85-90.
134. Komatsuda A, Wakui H, Nimura T, Sawada K. Reversible infliximabrelated lymphoproliferative disorder associated with Epstein-Barr virus in a patient with rheumatoid arthritis. Mod Rheumatol. 2008;18(3):315-318.

135. Park SH, Kim CG, Kim JY, Choe JY. Spontaneous regression of EBV-associated diffuse lymphoproliferative disease in a patient with rheumatoid arthritis after discontinuation of etanercept treatment. Rheumatol Int. 2008;28(5):475-477.

136. Balandraud N, Guis S, Meynard JB, Auger I, Roudier J, Roudier C. Long-term treatment with methotrexate or tumor necrosis factor alpha inhibitors does not increase Epstein-Barr virus load in patients with rheumatoid arthritis. Arthritis Rheum. 2007;57(5):762-767.

137. Lawlor G, Moss AC. Cytomegalovirus in inflammatory bowel disease: pathogen or innocent bystander? Inflamm Bowel Dis. 2010; 16(9):1620-1627.

138. Krech U, Jung M. Epidemiologie, Virologie und virologische Diagnose der Cytomegalie. Epidemiology, virology and virological diagnosis of cytomegaly. Klin Wochenschr. 1973;51(11):529-532. German.

139. Sissons JG, Carmichael AJ. Clinical aspects and management of cytomegalovirus infection. $J$ Infect. 2002;44(2):78-83.

140. Helbling D, Breitbach TH, Krause M. Disseminated cytomegalovirus infection in Crohn's disease following anti-tumour necrosis factor therapy. Eur J Gastroenterol Hepatol. 2002;14(12):1393-1395.

141. Haerter G, Manfras BJ, de Jong-Hesse Y, et al. Cytomegalovirus retinitis in a patient treated with anti-tumor necrosis factor alpha antibody therapy for rheumatoid arthritis. Clin Infect Dis. 2004; 39(9):e88-e94.

142. Papadakis KA, Tung JK, Binder SW, et al. Outcome of cytomegalovirus infections in patients with inflammatory bowel disease. $A m J$ Gastroenterol. 2001;96(7):2137-2142.

143. Sari I, Birlik M, Gonen C, et al. Cytomegalovirus colitis in a patient with Behcet's disease receiving tumor necrosis factor alpha inhibitory treatment. World J Gastroenterol. 2008;14(18):2912-2914.

144. Mizuta M, Schuster MG. Cytomegalovirus hepatitis associated with use of anti-tumor necrosis factor-alpha antibody. Clin Infect Dis. 2005;40(7):1071-1072.

145. Pontikaki I, Gerloni V, Gattinara M, et al. Effetti collaterali del trattamento con inibitori del TNF $\alpha$ nell'artrite idiopatica giovanile. Side effects of anti-TNFalpha therapy in juvenile idiopathic arthritis. Reumatismo. 2006;58(1):31-38. Italian.

146. van der Bij W, Schirm J, Torensma R, van Son WJ, Tegzess AM, The TH. Comparison between viremia and antigenemia for detection of cytomegalovirus in blood. J Clin Microbiol. 1988;26(12): 2531-2535.

147. Al-Zafiri R, Gologan A, Galiatsatos P, Szilagyi A. Cytomegalovirus complicating inflammatory bowel disease: a 10-year experience in a community-based, university-affiliated hospital. Gastroenterol Hepatol (N Y). 2012;8(4):230-239.

148. Shimojima Y, Ishii W, Matsuda M, Nakazawa H, Ikeda S. Cytomegalovirus-induced infectious mononucleosis-like syndrome in a rheumatoid arthritis patient treated with methotrexate and infliximab. Intern Med. 2010;49(10):937-940.

149. Palefsky J. Human papillomavirus infection in HIV-infected persons. Top HIV Med. 2007;15(4):130-133.

150. Walboomers JM, Jacobs MV, Manos MM, et al. Human papillomavirus is a necessary cause of invasive cervical cancer worldwide. J Pathol. 1999;189(1):12-19.

151. Tam LS, Chan AY, Chan PK, Chang AR, Li EK. Increased prevalence of squamous intraepithelial lesions in systemic lupus erythematosus: association with human papillomavirus infection. Arthritis Rheum. 2004;50(11):3619-3625.

152. Halpert R, Fruchter RG, Sedlis A, Butt K, Boyce JG, Sillman FH. Human papillomavirus and lower genital neoplasia in renal transplant patients. Obstet Gynecol. 1986;68(2):251-258.

153. Centers for Disease Control and Prevention. Human papillomavirusassociated cancers - United States, 2004-2008. MMWR Morbid Mortal Wkly Rep. 2012;61:258-261. 
154. Schiffman M, Castle PE, Jeronimo J, Rodriguez AC, Wacholder S. Human papillomavirus and cervical cancer. Lancet. 2007;370(9590): 890-907.

155. Nordgaard-Lassen I, Dahlerup JF, Belard E, et al. Guidelines for screening, prophylaxis and critical information prior to initiating anti-TNF-alpha treatment. Danish Med J. 2012;59(7):C4480.

156. Nissapatorn V, Sawangjaroen N. Parasitic infections in HIV infected individuals: diagnostic and therapeutic challenges. Indian J Med Res. 2011;134(6):878-897.

157. Derouich-Guergour D, Aldebert D, Vigan I, et al. Toxoplasma gondii infection can regulate the expression of tumour necrosis factor-alpha receptors on human cells in vitro. Parasite Immunol. 2002;24(5):271-279.

158. Young JD, McGwire BS. Infliximab and reactivation of cerebral toxoplasmosis. N Engl J Med. 2005;353(14):1530-1531.

159. Gonzalez-Vicent M, Diaz MA, Sevilla J, Madero L. Cerebral toxoplasmosis following etanercept treatment for idiopathic pneumonia syndrome after autologous peripheral blood progenitor cell transplantation (PBPCT). Ann Hematol. 2003;82(10):649-653.

160. Lassoued S, Zabraniecki L, Marin F, Billey T. Toxoplasmic chorioretinitis and antitumor necrosis factor treatment in rheumatoid arthritis. Semin Arthritis Rheum. 2007;36(4):262-263.

161. Lin MH, Chen TC, Kuo TT, Tseng CC, Tseng CP. Real-time PCR for quantitative detection of Toxoplasma gondii. J Clin Microbiol. 2000;38(11):4121-4125.

162. Portegies P, Solod L, Cinque P, et al. Guidelines for the diagnosis and management of neurological complications of HIV infection. Eur J Neurol. 2004;11(5):297-304.

163. Genta RM. Global prevalence of strongyloidiasis: critical review with epidemiologic insights into the prevention of disseminated disease. Rev Infect Dis. 1989;11(5):755-767.

164. Walker MD, Zunt JR. Neuroparasitic infections: nematodes. Semin Neurol. 2005;25(3):252-261.

165. Siddiqui AA, Berk SL. Diagnosis of Strongyloides stercoralis infection. Clin Infect Dis. 2001;33(7):1040-1047.

166. Walker M, Zunt JR. Parasitic central nervous system infections in immunocompromised hosts. Clin Infect Dis. 2005;40(7):1005-1015.
167. Keiser PB, Nutman TB. Strongyloides stercoralis in the immunocompromised population. Clin Microbiol Rev. 2004;17(1):208-217.

168. World Health Organization. Control of the leishmaniases. World Health Organ Tech Rep Ser. 2010;(949):xii-xiii, 1-186.

169. Kritikos K, Haritatos E, Tsigkos S, et al. An atypical presentation of visceral leishmaniasis infection in a patient with rheumatoid arthritis treated with infliximab. J Clin Rheumatol. 2010;16(1):38-39.

170. Tektonidou MG, Skopouli FN. Visceral leishmaniasis in a patient with psoriatic arthritis treated with infliximab: reactivation of a latent infection? Clin Rheumatol. 2008;27(4):541-542.

171. Fabre S, Gibert C, Lechiche C, Dereure J, Jorgensen C, Sany J. Visceral leishmaniasis infection in a rheumatoid arthritis patient treated with infliximab. Clin Exp Rheumatol. 2005;23(6):891-892.

172. Baltà-Cruz S, Alsina-Glbert M, Mozos-Rocafort A, Cervera C, Colomo-Saperas L, Del Río A, Estrach-Panella T. Pseudolymphomatoid cutaneous leishmaniasis in a patient treated with adalimumab for rheumatoid arthritis. Acta Derm Venereol. 2009;89(4):432-433.

173. Davidson RN, Russo R. Relapse of visceral leishmaniasis in patients who were coinfected with human immunodeficiency virus and who received treatment with liposomal amphotericin B. Clin Infect Dis. 1994;19(3):560.

174. Lewthwaite P, Gill GV, Hart CA, Beeching NJ. Gastrointestinal parasites in the immunocompromised. Curr Opin Infect Dis 2005;18(5):427-435.

175. Ford AC, Sandborn WJ, Khan KJ, Hanauer SB, Talley NJ, Moayyedi P. Efficacy of biological therapies in inflammatory bowel disease: systematic review and meta-analysis. Am J Gastroenterol. 2011;106(4):644-659.

176. Paltiel M, Gober LM, Deng A, et al. Immediate type I hypersensitivity response implicated in worsening injection site reactions to adalimumab. Arch Dermatol. 2008;144(9):1190-1194.

177. Cheifetz A, Smedley M, Martin S, et al. The incidence and management of infusion reactions to infliximab: a large center experience. Am J Gastroenterol. 2003;98(6):1315-1324.

178. Mazumdar S, Greenwald D. Golimumab. MAbs. 2009;1(5):422-431.
Drug, Healthcare and Patient Safety

\section{Publish your work in this journal}

Drug, Healthcare and Patient Safety is an international, peer-reviewed open-access journal exploring patient safety issues in the healthcare continuum from diagnostic and screening interventions through to treatment, drug therapy and surgery. The journal is characterized by the rapid reporting of reviews, original research, clinical, epidemiological and

\section{Dovepress}

post-marketing surveillance studies, risk management, health literacy and educational programs across all areas of healthcare delivery. The manuscript management system is completely online and includes a very quick and fair peer-review system. Visit http://www.dovepress.com/ testimonials.php to read real quotes from published authors. 